\title{
Statistical downscaling of the French Mediterranean climate: assessment for present and projection in an anthropogenic scenario
}

\author{
C. Lavaysse ${ }^{1}$, M. Vrac ${ }^{2}$, P. Drobinski ${ }^{1}$, M. Lengaigne ${ }^{3}$, and T. Vischel ${ }^{4}$ \\ ${ }^{1}$ Institut Pierre Simon Laplace/Laboratoire de Météorologie Dynamique, UMR8539, CNRS/Ecole Polytechnique/ENS \\ /UPMC, 91128 Palaiseau Cedex, France \\ ${ }^{2}$ Institut Pierre Simon Laplace/Laboratoire des Sciences du Climat et l'Environnement, UMR8212, CNRS/CEA/UVSQ, \\ 91198 Gif-sur-Yvette Cedex, France \\ ${ }^{3}$ Institut Pierre Simon Laplace/Laboratoire d'Océanographie et du Climat, Expérimentations et Approches Numériques, \\ UMR7159, CNRS/IRD/MNHN/UPMC, 75252 Paris Cedex 05, France \\ ${ }^{4}$ Laboratoire d'étude des Transferts en Hydrologie et Environnement, UMR5564, CNRS/G-INP/IRD/UJF, 38041 Grenoble \\ Cedex 9, France
}

Correspondence to: C. Lavaysse (lavaysse@ meteo.mcgill.ca)

Received: 15 February 2011 - Revised: 29 December 2011 - Accepted: 1 February 2012 - Published: 19 March 2012

\begin{abstract}
The Mediterranean basin is a particularly vulnerable region to climate change, featuring a sharply contrasted climate between the North and South and governed by a semi-enclosed sea with pronounced surrounding topography covering parts of the Europe, Africa and Asia regions. The physiographic specificities contribute to produce mesoscale atmospheric features that can evolve to high-impact weather systems such as heavy precipitation, wind storms, heat waves and droughts. The evolution of these meteorological extremes in the context of global warming is still an open question, partly because of the large uncertainty associated with existing estimates produced by global climate models (GCM) with coarse horizontal resolution ( $200 \mathrm{~km})$. Downscaling climatic information at a local scale is, thus, needed to improve the climate extreme prediction and to provide relevant information for vulnerability and adaptation studies. In this study, we investigate wind, temperature and precipitation distributions for past recent climate and future scenarios at eight meteorological stations in the French Mediterranean region using one statistical downscaling model, referred as the "Cumulative Distribution Function transform" (CDF-t) approach. A thorough analysis of the uncertainty associated with statistical downscaling and bi-linear interpolation of large-scale wind speed, temperature and rainfall from reanalyses (ERA-40) and three GCM historical simulations, has been conducted and quantified in terms of KolmogorovSmirnov scores. CDF-t produces a more accurate and reliable local wind speed, temperature and rainfall. Gener-
\end{abstract}

ally, wind speed, temperature and rainfall CDF obtained with CDF-t are significantly similar with the observed CDF, even though CDF-t performance may vary from one station to another due to the sensitivity of the driving large-scale fields or local impact. CDF-t has then been applied to climate simulations of the 21 st century under B1 and A2 scenarios for the three GCMs. As expected, the most striking trend is obtained for temperature (median and extremes), whereas for wind speed and rainfall, the evolution of the distributions is weaker. Mean surface wind speed and wind extremes seem to decrease in most locations, whereas the mean rainfall value decreases while the extremes seem to slightly increase. This is consistent with previous studies, but if this trend is clear with wind speed and rainfall data interpolated from GCM simulations at station locations, conversely CDF-t produces a more uncertain trend.

\section{Introduction}

The Mediterranean basin has a distinctive character that results both from physiographic conditions and historical and societal developments. The Mediterranean region generally defines the lands around the Mediterranean Sea that have a Mediterranean climate. This climate is characterised by hot, long and dry summers, mild winters during which rainfalls occur. Köpen (1936) defined the Mediterranean climate as one in which winter rainfall is more than three times the 
summer rainfall and Xoplaki et al. (2004) show that wet season precipitation from October to March, accounts for $20 \%$ (southern and eastern regions) and $30 \%$ (western and northern regions) of the annual total amounts. The medium to high mountains that surround the Mediterranean Sea play a crucial role in steering air flow and the Mediterranean Sea acts as a moisture and heat reservoir, so that energetic mesoscale atmospheric features can evolve to high-impact weather systems such as heavy precipitation during fall, cyclogenesis and wind storms during winter or heat waves and droughts during summer.

Indeed, the Mediterranean Basin records one of the highest concentrations of mid-latitude cyclones in the world, especially in winter (Petterssen, 1956). The Genoa region is the area of maximum cyclone concentration (e.g., Alpert et al., 1990; Trigo et al., 1999). In this area, the continental topography forces cyclonic developments often associated with strong local winds such as the Mistral and Tramontane (e.g., Drobinski et al., 2001, 2005; Guénard et al., 2005, 2006; Lebeaupin Brossier and Drobinski, 2009; Salameh et al., 2007). The Genoa low is mainly of lee cyclogenesis origin (Trigo et al., 1999).

In autumn, high SST of the Mediterranean Sea can destabilize air masses and favour latent heat release during cyclone formation which can produce heavy precipitations on the north-western Mediterranean basin (Ducrocq et al., 2002, 2008; Lebeaupin et al., 2006). Flooding associated with heavy precipitation, is one of the most devastating natural hazards in terms of human life loss along with windstorms. In France, over the last two decades, more than 100 deaths and several billions of euros damage was reported. In September 2002, flash floods in France brought additional losses of 1.2 billion euros (Huet et al., 2003). Conversely, Mediterranean summer is characterised by high temperatures, lack of rainfall and long periods of drought. The heat waves over Southern Europe result generally from a zone of strong high pressure over Western Europe that persists for many days (atmospheric blocking situation) and pushes Atlantic perturbations northwards. August 2003 has been classified as one of the warmest summer in Europe and had a major impact on excessive mortality rates in France. The persistent SST warm values and the amplitude of the blocking event over Europe are likely to be linked with this heat wave (Trigo et al., 2005).

The evolution of these meteorological extremes in the context of global warming is a key issue. This is not only for providing a tangible basis to the design of early warning procedures and mitigation measures to avoid the loss of life and reduce damage, but also for the assessment of their impacts on Mediterranean societies, which may be irreversible. Indeed, the area is very sensitive to climate change at short (decadal) and long (millennial) time scales. In Spain, Quereda Sala et al. (2000) reported an increase of the mean annual temperature of $0.5^{\circ} \mathrm{C}$ to $1.2^{\circ} \mathrm{C}$ between 1870 and 1996. A similar trend is observed in France (Moisselin et al., 2002).
When considering only the summer surface air temperature, the warming trend over Mediterranean region for the period 1950-1999 was $0.008^{\circ} \mathrm{C} \mathrm{yr}^{-1}$ (Xoplaki et al., 2003), reaching the value of $0.01{ }^{\circ} \mathrm{C} \mathrm{yr}^{-1}$ for $1976-2000$ (Solomon et al., 2007), one of the highest rates over the entire globe. The majority of the 21 st century scenarios shows a regional decrease in average precipitation with a peak signal in summer with either atmosphere-ocean Global Climate Models (GCM) (Giorgi and Bi, 2005), atmosphere Regional Climate Models (Gibelin and Déqué, 2003; Déqué et al., 2005; Gao et al., 2006; Ulbrich et al., 2006) or coupled atmosphere-ocean Regional Climate Models (RCM) (Somot et al., 2007). In winter, the agreement is weaker with some models showing an increase in precipitation. There is, however, no consensus on the evolution of the frequency and intensity of the extreme events over the Mediterranean regions, even though an increase in precipitation variability during the dry (warm) season is expected (Giorgi, 2006) and an increased probability of occurrence of events conducive to both floods and droughts is suggested (Gao et al., 2006). Globally, Giorgi (2006) defines the Mediterranean area as one of the two main "hot-spots" of the climate change with an increase in the interannual variability in addition to a strong warming and drying.

To obtain a deeper insight on the evolution of the extreme occurrence, intensity in a changing climate, there is a need to downscale climatic information at a local scale in order to provide relevant information for vulnerability and adaptation studies. Statistical downscaling is a computationally inexpensive method for obtaining local climate from GCMs by deriving statistical relationships between observed smallscale (often station level) variables and larger (GCM) scale variables. Statistical downscaling methods can generally be classified from one or more of the following sets of approaches, as was first suggested by Wilby and Wigley (1997): transfer functions, stochastic weather generators and weather typing. Transfer functions aim at translating directly largescale data into local-scale values through linear or nonlinear regressions. Given large-scale information $\boldsymbol{x}$, the downscaled local response $y$ is a function $\hat{y}(\boldsymbol{x})$ which usually estimates $E[Y \mid X=x]$. Among this regression-based approach, we can have: linear regression (e.g., Huth, 2002; Busuioc et al., 2008; Goubanova et al., 2010), nonlinear parametric models (such as polynomial regression, Sailor and $\mathrm{Xi}$ angshang, 1999), non-parametric regression based on generalized additive models (Vrac et al., 2007a; Salameh et al., 2009) and neural networks (e.g., Cannon and Whitfield, 2002; Haylock et al., 2006). Stochastic weather generators simulate meteorological variables, such as precipitation or temperature, based on probability density function (PDF) models (e.g., Semenov et al., 1998; Wilks, 1999). Weather generators are designed to simulate data with the same statistical properties as those from observations. In a downscaling context, weather generators simulate a local variable $Y$ conditionally on large-scale data $\boldsymbol{x}$, by building a model for 
the conditional distribution $Y \mid \boldsymbol{X}=\boldsymbol{x}$. To do so, the parameters of the pdf are functions of some appropriate large-scale information such as American weather regimes or North Atlantic Oscillation index (e.g., Vrac et al., 2007b; Yang et al., 2005), or other large-scale climate information (see Wilks and Wilby, 1999, for a review). Hence, large-scale changes are transferred to the local-scale density parameters and, as a consequence, the simulations can also evolve (Vrac and Naveau, 2007). The weather typing approach is based on clustering and classification of large-scale atmospheric circulation situations into recurrent weather patterns. Weather typing is based on the idea that a given circulation pattern is always associated to similar local-scale meteorological conditions (e.g., Zorita and von Storch, 1999; Huth, 2001). This approach can also serve as a pre-processing step before building transfer functions (e.g., Huth et al., 2008) or weather generators (e.g., Schnur and Lettenmaier, 1998; Vrac and Naveau, 2007).

In this article, we investigate wind, temperature and precipitation distributions on the French Mediterranean basin for recent climate and future scenarios at eight wisely distributed meteorological station locations (Fig. 1) using a new statistical downscaling model for the three variables, referred as the "Cumulative Distribution Function transform" (CDFT-t) approach, originally developed for wind downscaling (Michelangeli et al., 2009). This method aims at downscaling statistical characteristics using a probabilistic downscaling model. While classical statistical downscaling models generally directly provide local-scale values (e.g., see Maraun et al., 2010, for a recent review), probabilistic downscaling models link the cumulative distribution function (CDF) of a large-scale variable with the CDF of the same variable at a much smaller scale, and allow to downscale CDFs from which local-scale data can be generated. In that sense, CDF-t can be seen as a stochastic weather generator approach. In this study, we address the specific following issues:

- uncertainty assessment of the CDF-t method

- evaluation of CDF-t ability to reproduce distribution of extreme events (strong winds, heavy precipitation and hot temperatures)

- projection of statistical distribution of wind, temperature and rainfall in anthropogenic scenario, with a special focus on extreme event evolution.

These are key issues addressed in the frame of the MEDUP project (Forecast and projection in climate scenario of Mediterranean intense events: uncertainties and propagation on environment).

After the introduction in Sect. 1, Sect. 2 details the datasets and statistical method used in this study. Section 3 presents the calibration and validation of the method performed in the past recent climate decade and discusses the sources of uncertainty. The local projections of "future climates" obtained

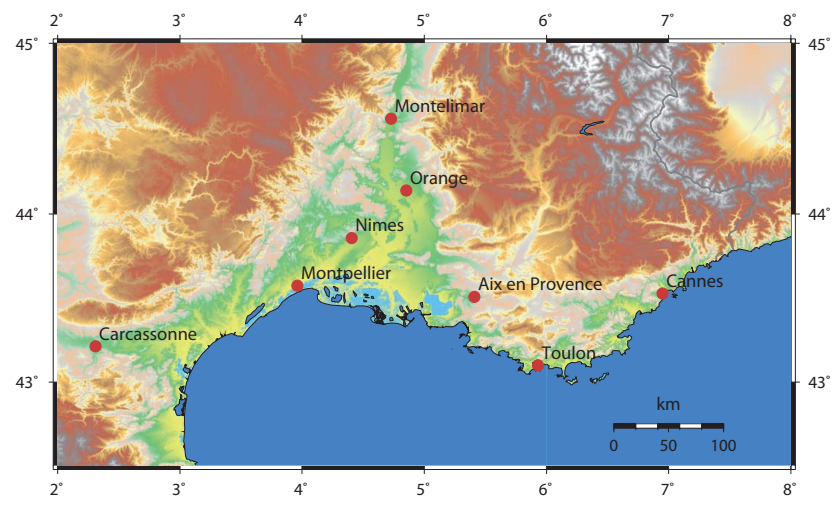

Fig. 1. Map of the studied region. The red dots indicate the locations of the surface weather stations from which wind speed, temperature and rainfall data are collected.

by downscaling atmospheric fields provided by three GCMs for emission scenarios B1 ("optimistic" emission scenario) and A2 ("pessimistic" emission scenario) are then analysed in Sect. 4. Section 5 concludes this study and points out some open research questions needing further investigations.

\section{Data and methodology}

\subsection{Station and large-scale data}

\subsubsection{Meteorological surface data}

As "station" data, we use the 10-m wind speed, 2-m temperature and rain data provided every $6 \mathrm{~h}$ by the Safran analysis system (Le Moigne, 2002) at locations where weather stations are localized. We selected stations spread over Southern France allowing the sampling of the various sub-climatic regions as in Salameh et al. (2009) (Fig. 1) and use the data provided by Safran in order to avoid "holes" in the data collected by the surface weather stations. The Safran analysis system had been initially designed to provide atmospheric forcing data in mountainous areas for avalanche hazard forecasting (Durand et al., 1993, 1999). The avalanche version of Safran has recently been used to develop a long-term meteorological reanalysis over the French Alps (Durand et al., 2009). This system has been extended over the whole country and modified in order to feed macroscale soil-vegetationatmosphere transfer models (Le Moigne, 2002). A detailed description of Safran, its validation and its application over France is given by Quintana-Seguí et al. (2008). The number of stations, used each day in SAFRAN, evolved with time (see Fig. 2 in Vidal et al., 2010). Continuously increasing from 3000 to 4000 observations per day for precipitation between the late 1950s to the present, the increase was much sharper for temperature and wind speed, with a jump from 500 to 4000 stations per day and from 500 to 2000 stations per day, respectively, between the late 1980s and the late 
1990s (no significant change since then). We kept a homogenized temperature and rainfall dataset over a 20 -yr period between 1981 and 2000 (only non-zero observed precipitation). Because of the important automation of the anemometers during the $1980 \mathrm{~s}$, which significantly modified the measurement of the wind speed (E. Martin, personal communication, 2008), we kept wind speed data over a $10-y r$ period between 1991 and 2000 .

\subsubsection{Large-scale data: reanalyses}

The European Center for Medium-Range Weather Forecast (ECMWF) has released reanalysed datasets for the time frame 1957-2002 (Simmons and Gibson, 2000). The ERA40 has a resolution corresponding to a T159 spectral truncation with 60 vertical levels from 1000 to $0.1 \mathrm{hPa}$. Data are reported on a $1.125^{\circ} \times 1.125^{\circ}$ grid every $6 \mathrm{~h}(00: 00,06: 00$, 12:00 and 18:00 UTC). In this study, the variables used are the mean daily wind speed at $10 \mathrm{~m}$ and $925 \mathrm{hPa}$, the mean daily temperature at $2 \mathrm{~m}$ and $925 \mathrm{hPa}$ and the daily cumulative precipitation, for the 1981-2000 period. To use large scale data onto stations, a simple bi-linear interpolation from the four nearest grid points of the model are used. This method provides a local value from large-scale temperature, wind speed and precipitation of the reanalysis.

\subsubsection{Large-scale data: climate models}

As part of the Intergovernmental Panel on Climate Change (IPCC) fourth assessment of climate change science released in 2007 (Solomon et al., 2007), a set of simulations from various global climate model experiments has been performed, evaluated and analysed in details in the frame of the Coupled Model Intercomparison Project No. 3 (CMIP3). Up to 23 GCMs contributed to the CMIP3 dataset. To avoid redundant information when the cumulative distribution functions are too close, we have used three available models (IPSL, Meteo-France and ECHAM5). This choice provides generally three different cumulative distribution functions of variables for the calibration and the projection periods owing to different model physics or schemes used. This allows analysing the behaviour and the sensitivity of the method following different tendencies and different predictors (such as variables and pressure levels). This subset of 3 GCMs providing daily outputs are used in this study as predictors for statistical downscaling for two contrasted emission scenarios for the 21st century (B1 and A2 scenarios corresponding to a mean global warming estimate for 2090-2099 relative to 1980-1999 of 1.8 and $3.4^{\circ} \mathrm{C}$, respectively; Solomon et al., 2007) (Table 1).

The A2 scenario is based on a very heterogeneous world with continuously increasing population and a technologically fragmented economic development leading to one of the highest emission scenarios available. In contrast, in B1 the emphasis is on global solutions to economic, social and environmental sustainability, and B1 is one of the lowest emission scenarios available. Historical simulations from the three GCMs (IPSL, CNRM and ECHAM5) over the 20th century have also been used as reference for the recent past climate. Daily data are, therefore, available from CMIP3 database for three time slices for which daily model predictors were available and downscaled: 1981-2000 (historical simulations), 2046-2065 and 2081-2100 (scenarios).

\subsection{The CDF-t method}

The downscaling method used in this study is the "Cumulative Distribution Function - transform" (CDF-t) method developed by Michelangeli et al. (2009). This approach aims at relating the cumulative distribution function (CDF) of a climate variable (e.g., wind or temperature) on a large scale (e.g., from GCM or reanalysis data) to the CDF of this variable on a local scale (e.g., at a station). This method is supplied by the bi-linear interpolation data to the stations provided by the GCMs, as explained previously. A mathematical transformation $T$ is, thus, applied to the large-scale CDF to define a new $\mathrm{CDF}$ as close as possible to the CDF measured at the station. Let $F_{\mathrm{Gh}}$ and $F_{\mathrm{Sh}}$ define, respectively, the CDFs of the variable of interest from the GCM and from a given station for a historical time period. We assume that the transformation $T$ allows to go from $F_{\mathrm{Gh}}$ to $F_{\mathrm{Sh}}$ :

$T\left(F_{\mathrm{Gh}}(x)\right)=F_{\mathrm{Sh}}(x)$.

Replacing $x$ by $F_{\mathrm{Gh}}^{-1}(u)$, where $u$ belongs to [0,1], we obtain

$T(u)=F_{\mathrm{Sh}}\left(F_{\mathrm{Gh}}^{-1}(u)\right)$,

which provides a simple definition of $T$. Assuming that this relationship is still valid under changed climate conditions, i.e., that $T$ is stationary in time, the transformation can be applied to $F_{\mathrm{Gf}}$, the large-scale $\mathrm{CDF}$ of the climate variable for a future time period, to generate $F_{\mathrm{Sf}}$, the $\mathrm{CDF}$ at the station for the same future time period:

$T\left(F_{\mathrm{Gf}}(x)\right)=F_{\mathrm{Sf}}(x)$,

which is equivalent to

$F_{\mathrm{Sf}}(x)=F_{\mathrm{Sh}}\left(F_{\mathrm{Gh}}^{-1}\left(F_{\mathrm{Gf}}(x)\right)\right)$.

In the following, all computations for this CDF downscaling have been made through the "CDF-t" R package (freely available on www.r-project.org). More theoretical and technical details, as well as first validations and comparisons can be found in Michelangeli et al. (2009), while an application of CDF-t to local projections of precipitation and temperature over India is provided in Vigaud et al. (2010).

While CDF-t is directly used for temperature and wind variables, two different processings are applied and tested to the rainfall dataset in order to downscale the CDF of strictly 
Table 1. Global climate models from CMIP3 database to which CDF-t statistical downscaling method is applied. Their grid size and sensitivity $\Delta T$ are shown in the last two columns. Their sensitivity is calculated using the global warming produced by the model using the A1B scenario when approximated by linear regression over the 21st century (CSIRO and Bureau of Meteorology, 2007 CSIRO and Bureau of Meteorology, Climate Change in Australia, Technical Report, Australian Greenhouse Office (2007) www.climatechangeinaustralia.gov.au, 148 pp., CSIRO and BoM, 2007).

\begin{tabular}{lllcc}
\hline Originating group & Country & Acronym & Grid size $(\mathrm{km})$ & $\Delta T\left({ }^{\circ} \mathrm{C}\right)$ \\
\hline Institut Pierre Simon Laplace & France & IPSL & $\sim 300$ & 3.19 \\
Météo-France & France & CNRM & $\sim 200$ & 2.81 \\
Max Planck Institute for Meteorology & Germany & ECHAM5 & $\sim 200$ & 3.69 \\
\hline
\end{tabular}

positive rainfall. Two different thresholds are defined here to differentiate "rain" and "no rain" events. The first processing consists of retaining only non-zero values in both the observed and GCM rainfalls. In the second processing, only non-zero values are retained for the observed data, but a new threshold, larger than zero, is selected for each GCM (G) and station (S). This new threshold $t_{\mathrm{GS}}$ is defined in order to keep the same number of days from the GCM as the number of days with $>0$ rainfall at station $\mathrm{S}$. In other words, the threshold $t_{\mathrm{GS}}$ is determined that

$F_{\mathrm{Gh}}\left(t_{\mathrm{GS}}\right)=F_{\mathrm{Sh}}(0)$.

This threshold is defined for each season and station, and allows removing GCM days with low cumulated rainfall (generally these daily cumulated rainfalls are close to zero). In processing 1 , the assumption is that the model does not well estimate the occurrence of precipitation, but is able to reproduce the good distribution of precipitation amounts. The assumption of processing 2 is that the model reproduces neither the precipitation occurrence nor the distribution, but estimates accurately the tendency between the calibration and the projection periods, with a strong focus on the strongest rainfalls.

\section{Assessment for present climate}

\subsection{Calibration and uncertainty evaluation}

The uncertainty evaluation is performed using two different time periods: one for the calibration of CDF-t, one for projections and evaluations. As indicated in Sect. 2.1.1, the observed temperature and rainfall data cover a $20 \mathrm{yr}$ period, whereas wind speed only spans $10 \mathrm{yr}$. These periods have been split into two periods of equal length. Calibration is performed on 1981-1990 for temperature and precipitation and 1991-1996 for wind speed; projections and evaluations are performed on 1991-2000 (temperature and rain) and 19962000 (wind) periods.

The uncertainty quantification of the downscaling method, which is a major objective of the MEDUP project, is performed by comparing the time series calculated from the downscaled CDF with the observed ones. This is quantified over each station and variables using the KolmogorovSmirnov score (KS) using different GCM outputs and pressure levels. Indeed, the KS can be seen as a measure of the distance between two CDFs, as already used in previous downscaling validation studies (e.g., Darling, 1957; Michelangeli et al., 2009). The agreement of these KS scores the downscaling CDF, following different models and pressure levels, is defined as a proxy of the uncertainty. Moreover, a large part of these results have been validated using the Cramer Von Misses method and displayed the same significance. If $F(x)$ is the empirical CDF of the observed data in the evaluation period (i.e., the CDF to be retrieved), and $F_{\mathrm{Sf}}(x)$ the downscaled CDF, the KS statistics is the supremum of the absolute differences between $F$ and $F_{\mathrm{Sf}}$ :

$\mathrm{KS}=\sup _{x}\left|F_{\mathrm{Sf}}-F(x)\right|$.

In the following, the KS score is computed to compare the observed CDF with (i) the CDF of the interpolated largescale fields from ERA-40 reanalyses and CMIP3 control runs (for the three GCMs) and (ii) the CDF obtained from the CDF-t statistical downscaling method.

In order to visualise the evolution of the CDFs between the two periods (calibration and projection), Fig. 2 shows the KS values quantifying the difference between the CDFs of the evaluation period (1991-2000 for temperature and precipitation; 1996-2000 for wind speed) and those of the calibration period (1981-1990 for temperature and precipitation; 19911996 for wind speed).

The areas of the circles are proportional to the KS values. For a confidence level $\alpha$ in $[0,1]$, when the KS values are larger than a theoretical threshold value $\mathrm{KS}_{\alpha}$, the two CDFs significantly differ at level $\alpha$. This theoretical threshold value $\mathrm{KS}_{\alpha}$ is defined by:

$\operatorname{Pr}\left(\mathrm{KS} \leq \mathrm{KS}_{\alpha}\right)=1-\alpha$.

In Fig. 2, the black circles represent the KS values computed between the CDFs of the observations during the calibration period and those during the evaluation period, whereas the coloured circles represent the equivalent $\mathrm{KS}$ values (i.e., calibration vs. evaluation) for the interpolated 


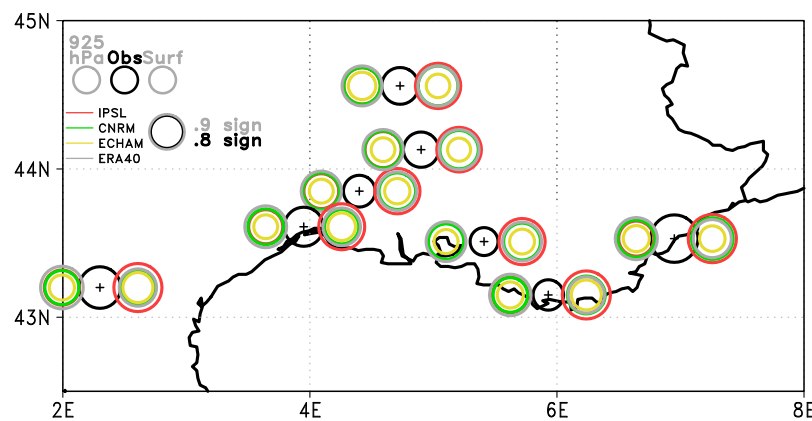

(a) Temperature

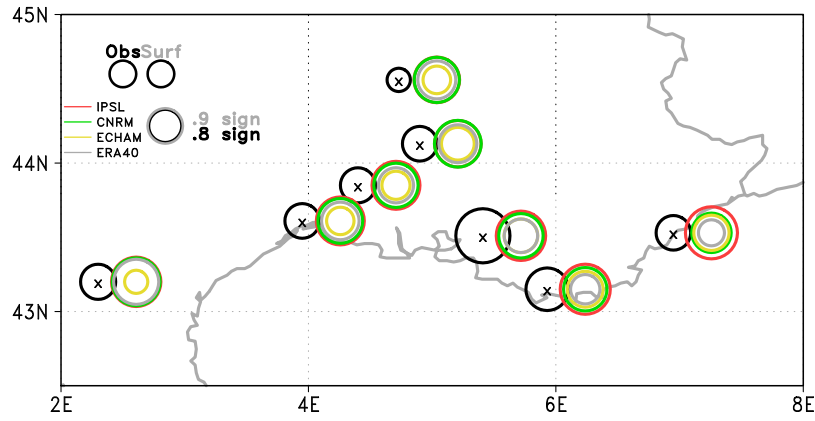

(c) $>0$ rainfall (processing 1)

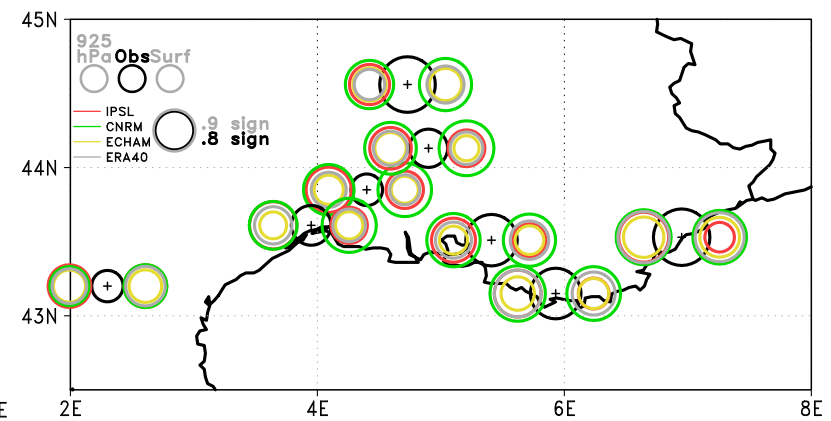

(b) Wind

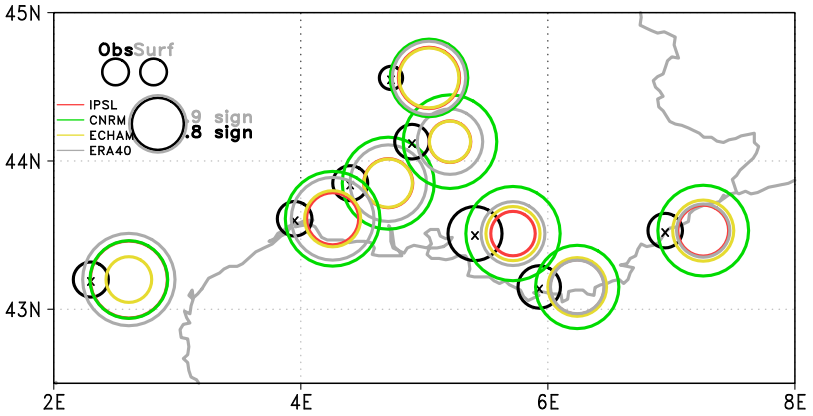

(d) $>$ threshold rainfall (processing 2)

Fig. 2. KS scores (proportional to the circle areas) comparing the CDFs over the evaluation period (1991-2000 for temperature and precipitation; 1996-2000 for wind speed) and over the calibration period (1981-1990 for temperature and precipitation; 1991-1996 for wind speed) for temperature (a), wind speed (b), rainfall (processing 1 in (c); processing 2 in (d); see details in the text for the definition of rainfall processing). In panels (a) and (b), the KS scores for the observations are displayed in the middle, for the model using the $925 \mathrm{hPa}$ data on the left, and for the surface fields on the right. In panels (c) and (d), the KS scores for the observations are displayed on the left and for the model on the right. The KS scores are computed over the eight stations using IPSL (red), CNRM (green), ECHAM5 (yellow) and ERA reanalyses (grey).

ERA-40 reanalyses and the three CMIP3 control runs at the surface weather station locations. When the coloured circles are larger than the black circles, the difference between the CDFs of the interpolated data from the two periods is larger than the difference between the CDFs from the observations over the two periods. The $80 \%$ and $90 \%$ confidence levels of the KS are indicated in the legend. For wind and temperature, large-scale predictors are considered for two different vertical levels (at the surface and at $925 \mathrm{hPa}$ ). The surface predictor fields are expected to be closer to the surface observations than the $925 \mathrm{hPa}$ fields, however, they are also more affected by the coarse resolution of the topography, surface heterogeneities and by the specific selection of the physical parameterisations (like surface or boundary layer). Thus, this sensitivity test may quantify the ability of the surface level to well represent the local characteristics. For temperature (Fig. 2a), we note that except for Cannes and Carcassonne, CMIP3 models and ERA reanalyses depict very close results and display a larger difference (i.e., larger KS) between the two periods than observed, especially when using the surface temperature. In general, $\mathrm{KS}$ values with the $925 \mathrm{hPa}$ temperature are smaller than with the sur- face temperature and are in better agreement with the observations. For wind speed (Fig. 2b), the spread of the KS values from the different models is larger than for temperature. This could be due to an evolution between the two periods which is larger for wind speed CDF than for temperature, or a larger sensitivity of wind speed CDF to local characteristics. The CNRM GCM displays the largest $\mathrm{KS}$ value for all stations. On average, the use of surface or $925 \mathrm{hPa}$ wind speed does not induce significant difference on the KS values. This result might have different causes including; the quality of the parameterisation, the GCM resolution, which tend to limit the regional effects and the downscaling methodology. Intuitively, there is no straightforward link between the quality of the parameterisation and the fact that the KS are similar when using the surface data or the $925 \mathrm{hPa}$. Since the GCMs do not have the same parameterisations advocates for a weak effect. The coarse resolution of the large-scale field (ERA-40 and GCM) seems the main obstacle for a much better downscaling performance. At such coarse resolution $(>100 \mathrm{~km})$, the surface representation is generally poor, which tends to limit the interest of considering the surface level instead of the $925 \mathrm{hPa}$ level. The 


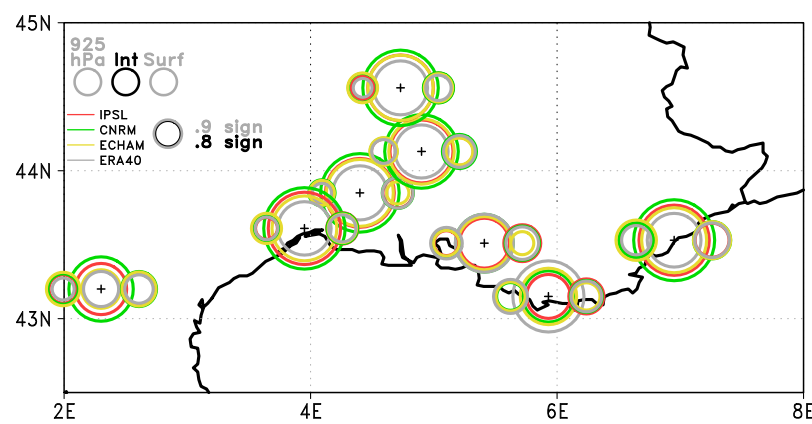

(a) Temperature

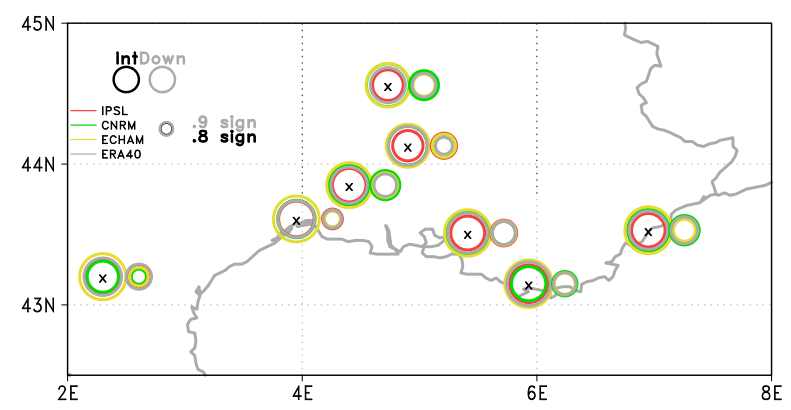

(c) $>0$ rainfall (processing 1)

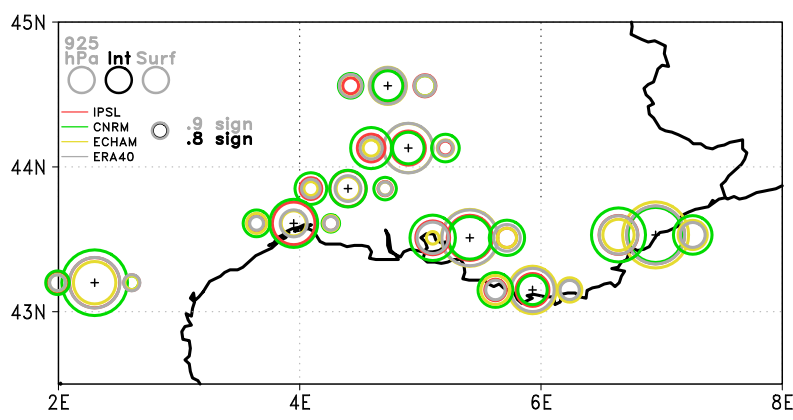

(b) Wind

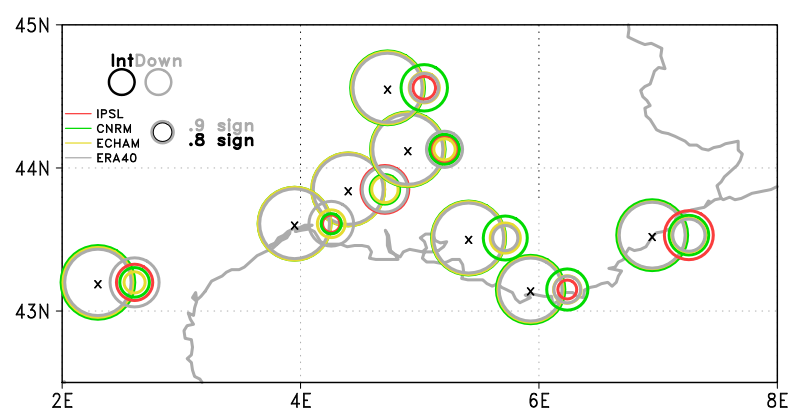

(d) $>$ threshold rainfall (processing 2)

Fig. 3. KS values computed for the validation period between the CDFs of the observed data and the CDFs of the interpolated GCM data (centre circles), or the downscaled CDFs using the $925 \mathrm{hPa}$ field (for temperature and wind speed, left circles) or the surface fields (right circles), for (a) temperature, (b) wind, (c) > 0 rainfall from processing 1, and (d) threshold rainfall from processing 2 (see text for details). The colour of the circles indicates the source of the large-scale fields: IPSL (red), CNRM (green), ECHAM5 (yellow), and ERA40 (grey). The areas of the circle are proportional to the value of the KS score.

only reliable conclusion is that whatever the vertical level, CDF-t corrects in the same way (with two different transfer functions $T$; see Eq. 3), the large-scale CDF with the observations over the calibration period. Additionally, there may be issues with the statistical method used which include the ability of the method to estimate the downscaled CDF from an extended large-scale CDF (e.g., with a larger range and variability), as is the case for the surface. The KS values are similar to those computed from the observations collected in the centre and in the eastern part of the investigated region whereas they exceed the KS values computed from the observations collected in the western part of the domain. For rainfall (Fig. 2c and d), the method with only non-zero precipitation (processing 1) displays KS values similar to those obtained from the observed rainfall whereas the KS scores are larger with the method accounting for a rainfall threshold (processing 2). This does not mean that processing 1 is better than processing 2 since $\mathrm{KS}_{\alpha}$ increases when the number of data from GCM decreases (i.e., larger $\mathrm{KS}_{\alpha}$ in processing 2).

The occurrence of precipitating events, selected with processing 1 (non-zero rainfall), is larger with the interpolated large-scale precipitation (CMIP3 models and ERA reanalyses) than with the observed rainfall (Table 2). The occurrence of observed rainfall increases over validation period relative to the calibration period while the opposite behaviour is found when using the interpolated and downscaled largescale fields. By construction, CDF-t rainfall occurrence also decreases since driven by the interpolated large-scale precipitation.

Using processing 2 (threshold rainfall), the interpolated rainfall occurrence is by construction equal to the observed rainfall occurrence (i.e., 0.15 ) over the calibration period. As with processing 1 , the decrease of large-scale precipitation occurrence also leads to a decrease of the CDF-t downscaled rainfall occurrence, but the comparison with observed rainfall occurrence is still acceptable (0.13-0.14, i.e., about $10 \%$ difference).

Figure 3 shows the KS values comparing at each station the CDFs of the observed data and the CDFs of the interpolated large-scale fields (ERA-40 reanalyses and CMIP3 control runs; "Int" circles in Fig. 3) over the evaluation period (1991-2000 for temperature and precipitation; 1996-2000 for wind speed). It also displays the KS values comparing the CDFs of the observed data and the CDFs of the CDF-t downscaled data (from ERA-40 reanalyses or CMIP3 control runs; "925 hPa" and "Surf" circles for wind speed and temperature in Fig. 3a and b; "Down" circles for rainfall in Fig. $3 \mathrm{c}$ and d). 
Table 2. Occurrence of precipitating events for each model and over the calibration period 1981-1990 (columns 2 and 4), and the validation period 1991-2000. Columns 2 and 3, and 4 and 5 correspond to processing 1 (non-zero precipitation) and processing 2 (threshold precipitation), respectively. The values between brackets correspond to those produced by CDF-t.

\begin{tabular}{lcccc}
\hline \multirow{2}{*}{ Model } & \multicolumn{2}{c}{ Processing 1 } & \multicolumn{2}{c}{ Processing 2 } \\
& Calibration period & Validation period & Calibration period & Validation period \\
\hline Observations & 0.15 & 0.167 & 0.15 & 0.167 \\
IPSL interp. (down) & 0.81 & $0.76(0.76)$ & 0.15 & $0.15(0.13)$ \\
CNRM interp. (down) & 0.98 & $0.98(0.92)$ & 0.15 & $0.15(0.14)$ \\
ECHAM interp. (down) & 0.67 & $0.66(0.65)$ & 0.15 & $0.15(0.13)$ \\
ERA40 interp. (down) & 0.66 & $0.62(0.59)$ & 0.15 & $0.15(0.13)$ \\
\hline
\end{tabular}

The KS values of the interpolated data are by far the largest (circles in the middle in Fig. 3a and b; circles on the left in Fig. 3c and d). The CDFs of the interpolated data at most stations deviate substantially from the observed CDFs (even with ERA-40 reanalyses). This expected result confirms the necessity for appropriate downscaling tools. The KS values obtained using CDF-t are much smaller, whatever the atmospheric variable or predictor level $(925 \mathrm{hPa}$ and surface levels). In many stations, the $\mathrm{KS}$ values are very close to the KS threshold, evidencing the absence of significant difference between the downscaled CDFs and the observed CDFs.

Table 3 indicates with a letter (I=IPSL, C=CNRM, $\mathrm{E}=\mathrm{ECHAM}$, R=ERA-40), which large-scale data, used as inputs of CDF-t, provides downscaled CDFs considered as similar to the observations over the validation period with a $80 \%$ confidence level $(90 \%$ confidence level in red; Note that a confidence at a $80 \%$ level implies a confidence at the $90 \%$ level). It shows that downscaling rainfall is less accurate than downscaling temperature or wind. Using threshold rainfall (i.e., processing 2) improves the quality of the downscaling, i.e., reproduces the tendency of the rainfall distribution better for the largest rainfalls than the evolution of the rainfall distribution close to 0 (processing 1). It also shows that the results can vary significantly between the stations. For instance, at Carcassonne, CDF-t provides accurate downscaled wind, temperature and precipitation for nearly all large-scale fields, whereas at Cannes, the quality of the downscaled variables is extremely low. These differences can be attributed to the immediate environment of the surface weather station. Indeed, a steep topography can produce a local response that may partly be disconnected from the largescale circulation, inducing larger KS values. Another cause of difference may be the modification of the environment of the station (e.g., land cover) or of the sensor itself. However, for temperature and wind, CDF-t can be used satisfactorily at most stations with the large-scale fields from at least one GCM and ERA-40. Figure 3 also shows that, for temperature (Fig. 3a), the $925 \mathrm{hPa}$ level data generally improves the quality of the downscaling, whereas it is the reverse for wind at most stations (Fig. 3b). For rainfall (Fig. 3c and d), the KS values in the absence of threshold are spatially homogeneous and independent of the large-scale fields (ERA-40 reanalysis or CMIP3 control runs). In the presence of threshold, the $\mathrm{KS}$ values are more variable in space and also more sensitive to the large-scale fields. This increase of sensitivity could be associated with the truncation of low precipitation events which are very similar and quite stationary in the three models. The large number of low precipitation tends to reduce the spatial variability of the KS scores and the difference between models. Using only the $16 \%$ largest rainfall events produces larger spatial variability and more sensitivity to the large-scale field model (because of different convection and microphysics parameterisations for instance). Nevertheless, using the two processing, the KS values for the downscaled and observed rainfall CDFs are larger than the threshold at $90 \%$ confidence level, evidencing a significant difference between the CDFs. Thus, it seems that both processing 1 and 2 can not compensate the poor quality of the GCM rainfall and the incorrect trend of the model between the two periods, generally too large with respect to the observations (not shown).

The ability of the GCMs and CDF-t to simulate and downscale wind speed, temperature and precipitation may depend on the seasons. Indeed, in winter, weather over the French Mediterranean basin is essentially driven by baroclinic instabilities, so rainfall, temperature and wind are mainly controlled by large-scale atmospheric circulation. However, interaction with the regional complex terrain generates atmospheric response at mesoscale that can not be reproduced by simple interpolation at surface weather station locations (not shown). In summer, although the large-scale forcing still influences the surface weather, local forcing becomes non negligible, and at times even predominant. As a consequence, the interpolated large-scale fields display differences between CDFs from interpolations and observations larger in summer than in winter (not shown). As for the whole year, $\mathrm{CDF}$-t improves significantly the KS values for all variables and all seasons. The maps of the KS values for winter and summer look like that of Fig. 3 (not shown). However, in detail, Table 3 shows that, in term of significance, small differences exist between seasons and the whole year at specific locations. 
Table 3. For each station, variable, and period of the year, the letters indicate the large-scale data $(\mathrm{I}=\mathrm{IPSL}, \mathrm{C}=\mathrm{CNRM}, \mathrm{E}=\mathrm{ECHAM} 5$, $\mathrm{R}=$ ERA-40) which provide downscaled CDFs considered by the KS-test as similar to the observations for the validation period with a $80 \%$ confidence level (90\% confidence level in red).

\begin{tabular}{|c|c|c|c|c|c|c|c|c|c|}
\hline \multirow{2}{*}{ Variable } & \multirow{2}{*}{ Season } & \multicolumn{8}{|c|}{ Stations } \\
\hline & & Cannes & Nimes & Orange & Toulon & Carcas & Aix en $P$ & Montelim & Montpel \\
\hline \multirow{3}{*}{ Temperature } & Whole year & ICR & ICER & ICER & ICER & ICER & ICER & ICER & ICER \\
\hline & Winter & $\mathrm{E}$ & ICER & CER & ICE & $\mathrm{R}$ & ICE & CER & CER \\
\hline & Summer & IC & ICER & ICER & ICR & ICER & ICER & ICER & ICER \\
\hline \multirow{3}{*}{ Wind speed } & Whole year & & ICER & IER & ICR & IER & IER & IER & ICER \\
\hline & Winter & & IER & $\mathrm{R}$ & IER & ICER & IR & ICER & IER \\
\hline & Summer & $\mathrm{R}$ & CER & ER & ER & ICER & & CER & CER \\
\hline \multirow{3}{*}{ Rain (processing 1) } & Whole year & & & $\mathrm{R}$ & & $\mathrm{C}$ & & & \\
\hline & Winter & & & IR & & IR & $\mathrm{R}$ & & \\
\hline & Summer & & & & & & & & \\
\hline \multirow{3}{*}{ Rain (processing 2) } & Whole year & & $\mathrm{E}$ & IE & IER & E & IR & I & ICER \\
\hline & Winter & $\mathrm{C}$ & & IR & $\mathrm{CR}$ & IC & $\mathrm{R}$ & IR & I \\
\hline & Summer & $\mathrm{R}$ & $\mathrm{C}$ & $\mathrm{CE}$ & CER & CIE & E & $\mathrm{CE}$ & $\mathrm{CE}$ \\
\hline
\end{tabular}

\subsection{Extreme events}

In this section, we focus on the ability of the GCM and CDF$t$ method to correctly estimate the rate of occurrence of extreme events, which is another key objective of the MEDUP project. Here, we define extreme events as values exceeding the $95 \%$ quantile of the observations. We compute the probability of having interpolated and downscaled data larger than this quantile over the projection period (1991-2000). An accurate reproduction of the extremes would be reached if this probability is close to $5 \%$. Figure 4 displays those probabilities at all surface weather stations for interpolated and downscaled (using both, the $925 \mathrm{hPa}$ and the surface layers) data.

For temperature (Fig. 4a), interpolation of CMIP3 model fields and ERA-40 reanalyses underestimates the number of extreme events (red markers close to 0). The CDF-t method displays much better scores, closer to the $5 \%$ probability (blue and green markers). Slight underestimation of temperature extremes is found when large-scale surface temperature is used as predictors (green markers). In agreement with the results of previous sections, it gets better when using the $925 \mathrm{hPa}$ large-scale temperature as predictors (blue markers). For wind speed (Fig. 4b), interpolation gives very heterogeneous results with respect to the location. For instance, at Cannes, all models overestimate the extremes, whereas at Carcassonne, there is a large underestimation. More generally, the eastern region (i.e., Cannes, Toulon, Orange and Aix en Provence) displays an overestimation of wind extremes, whereas the western region (i.e., Carcassonne, Montpellier, Nimes) displays an underestimation of the wind extremes. Indeed, in situations of strong offshore winds like Mistral and Tramontane (Drobinski et al., 2001, 2005), the smoothed orography in the models does not allow the upstream blocking and channeling of the north/northwesterly air mass impinging on the Alps which, thus, flows over the mountain range. Observations and high-resolution simulation show that such meteorological situations lead to the formation of a wake behind and close the Alpine massif, which is a stagnation zone where the wind speed is very low (Drobinski et al., 2005; Guénard et al., 2006). This could explain the overestimation of wind extremes south of the Alps in the interpolated large-scale surface winds. Contrary to interpolation, CDF-t is less variable and is able to correctly represent the extreme events with percentage of occurrence close to 0.05 . Indeed, the strength and direction of the large-scale surface wind interpolated at the surface weather station location are related to the strength and direction of the flow upstream of the Alps (because of the too smoothed orography), which drive the formation of the wake trailing downstream. A statistical relationship is, thus, possible between the large-scale wind CDF and the local-scale one. For rainfall, both processings allow a more accurate representation of the extreme events with CDF-t than with interpolation. The interpolation method tends to underestimate the number of extreme events and overestimate the low precipitation. This is due to the spatial resolution of the GCMs. Nevertheless, CDF-t tends to provide a good estimation of the percentage of extreme events higher than the $95 \%$ quantile. This ability could be due to the constant underestimation of GCM to generate large amounts of rainfall. This constant underestimation in both periods is corrected by CDF-t and allows the method to provide a percentage between 0.04 and 0.06 for processing 1 . Using the second processing, the truncation of the 


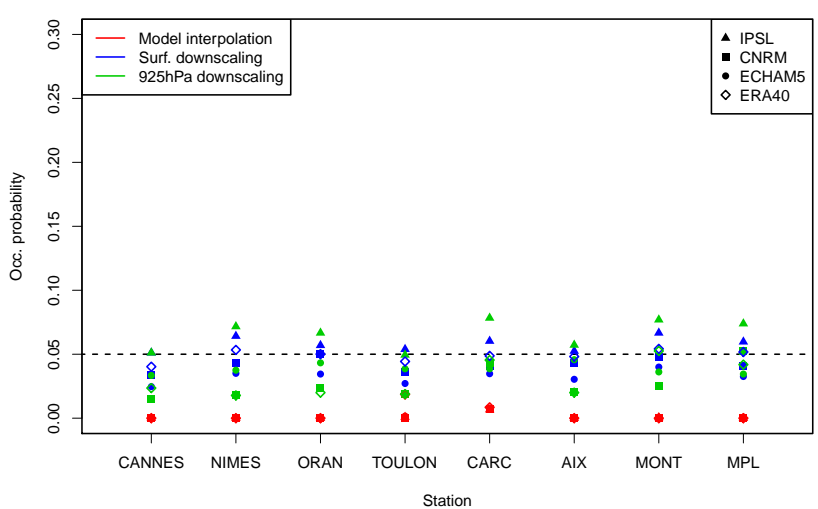

(a) Temperature

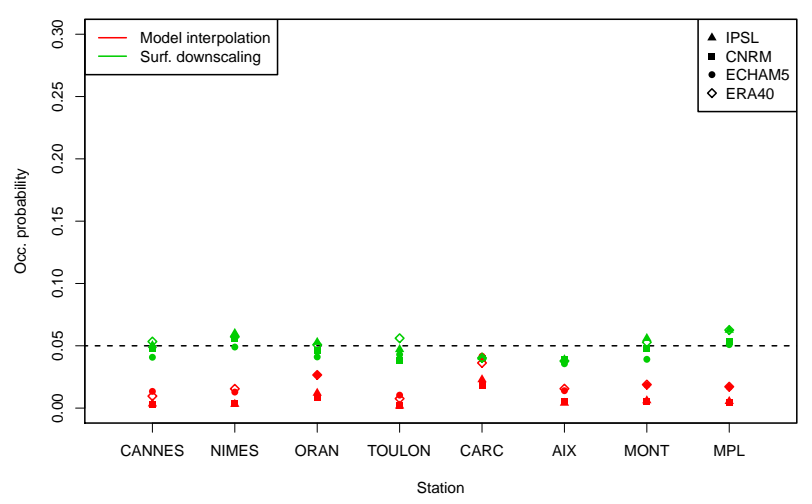

(c) $>0$ rainfall (processing 1)

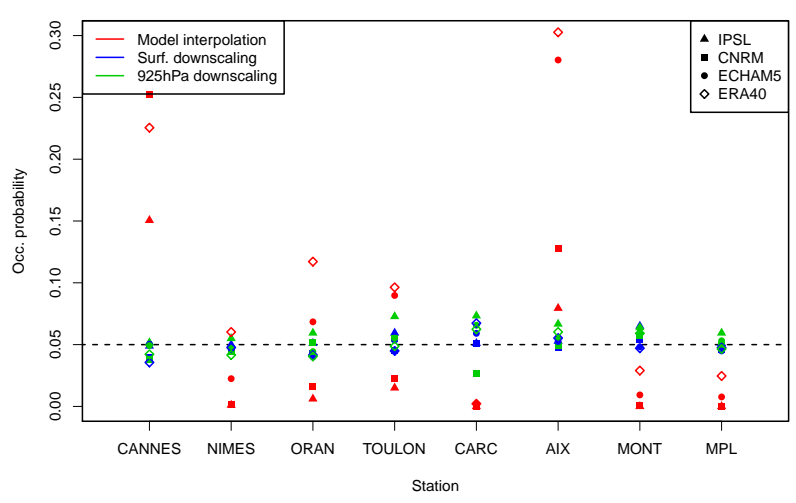

(b) Wind

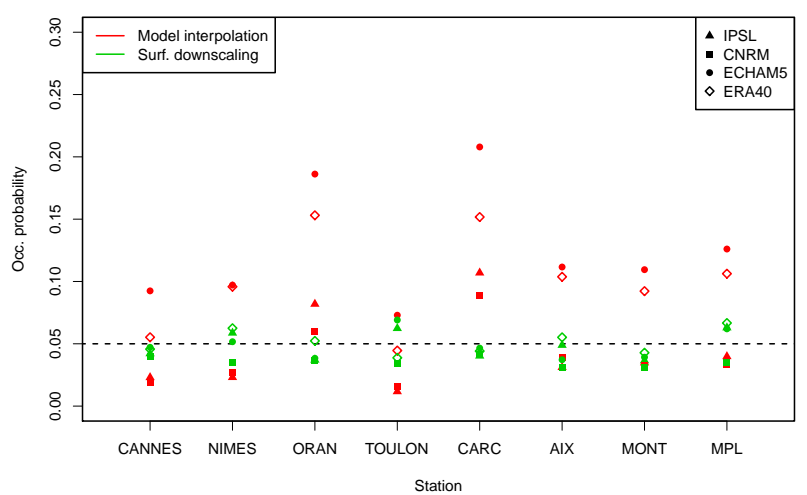

(d) $>$ threshold rainfall (processing 2)

Fig. 4. Probability of having interpolated and downscaled data, at $925 \mathrm{hPa}$ and surface levels (in red, blue and green respectively) from models and reanalyses larger than the $95 \%$ quantile of the observations for the validation period. The signs indicate the model used, triangle for IPSL, square for CNRM, circle for ECHAM5 and empty diamond for ERA40. The dashed lines correspond to the $5 \%$ occurrence probability.

CDF from the GCMs produces a strong bias when the interpolation method is used. With the downscaling method, this bias does not interfere and the results are close to those from processing 1 (percentage between 0.03 and 0.07 ), with a slightly larger variability depending on the stations and the models, due to the decrease of the number of events taken into account in processing 2 .

Since the extreme events are of a different nature when considering winter or summer seasons, similar probabilities of exceedances were computed for winter and summer (not shown). The analysis of the interpolated large-scale surface wind extremes is similar for winter than for the whole year, however, with more frequent and stronger extremes with respect to summer. Indeed, Mistral and Tramontane are stronger and slightly more frequent in winter than in summer (e.g., Drobinski et al., 2005; Guénard et al., 2006). For temperature, CDF-t improves considerably the modelling of extremes, underestimated by the climate models. However, in details, downscaled temperature extremes are slightly un- derestimated in winter, whereas they are overestimated in summer. This is particularly true when IPSL model is used as input for CDF-t. For precipitation, the probability of occurrence of extremes is slightly underestimated in winter using the interpolation method. During this period, the CDF$\mathrm{t}$ method improves the results that are close to 0.05 (not shown). In summer, the interpolation method strongly underestimates extreme events (always less than 0.03 occurrence probability). The CDF-t method partially corrects this ratio, but still remains generally lower than 0.05 (not shown).

\subsection{Comparison between CDF-t and quantile-mapping}

To compare CDF-t with a more classical downscaling method (such as the SDSM weather generator Wilby et al. (2002), or a weather typing-based scheme, Boé et al. (2006)), it is necessary to consider the type, size and number of predictors required, in other words, the complexity of the methods to be compared. Indeed, whereas most of 
the statistical downscaling methods need several predictors over a gridded area, the CDF-t approach provides the distribution of a given local-scale variable using only the same (i.e., one) variable at a large scale (from GCM or reanalyses). For example, fields of temperature, humidity and sealevel pressure are frequently used as predictors to downscale precipitation, whereas CDF-t provides locale-scale precipitation only from large-scale precipitation data. Hence, the comparison between CDF-t and a more frequently used statistical downscaling method would not be wholly meaningful, since it would be difficult to distinguish the features of the simulations from the statistical downscaling method itself or from the use of more informative predictors. However, Quintana-Seguí et al. (2011) have compared the quantilemapping (QM) method (Panofsky and Brier, 1958; Haddad and Rosenfeld, 1997; Déqué, 2007; Maurer and Hidalgo, 2008) and a weather typing method (Boé et al., 2006) and have shown that these two approaches are able to reproduce the observed extremes of precipitation in the Southern part of France, except over the Cevennes region. The QM method has a similar philosophy as CDF-t since it works also on CDFs. With the same notations as previously, for each largescale value $x$ from the projection period, QM seeks the localscale value, say $y$, such that $F \operatorname{Sh}(y)=F \mathrm{Gh}(x)$. Hence, this method uses the same data as CDF-t to downscale climate variables. It is, therefore, an appropriate model to compare CDF-t with. Note that other variants of QM could have been employed (for example, see Li et al., 2010).

Figure 5 shows boxplots of KS scores computed between the CDF of the observations at the eight stations over the validation period and the ERA40-downscaled CDFs, from both CDF-t and QM, for temperature, wind speed and rainfall in winter (summer results are not shown but indicate that both methods globally provide CDFs of similar quality).

For temperature, CDF-t performs better than QM while for wind QM seems to perform slightly better than CDF-t. However, due to the relatively small number of stations (eight) to construct the boxplots, it is difficult to provide a robust conclusion and the two methods give similar results. The results are also equivalent for the three GCMs (not shown) but the two methods have difficulties at more than half of the stations to produce correct local-scale wind CDFs with CNRM simulations. For precipitation, while QM may give some correct CDFs (i.e., with KS scores under the solid red line), CDF-t generally provides CDFs that cannot be considered as similar as the observed ones. Indeed, GCMs and ERA40 rainfall data have seen evolutions of their CDF between the calibration and the validation period. However, the observations do not show this type of evolution. By construction, CDFs produced by the QM method cannot depart too far away from the CDFs computed over the calibration period. Hence, although the statistical properties of the large-scale data have changed, the downscaled data stay relatively close to the calibration data. On the opposite, CDF-t follows the large-scale CDFs evolutions. If those evolutions are incorrect

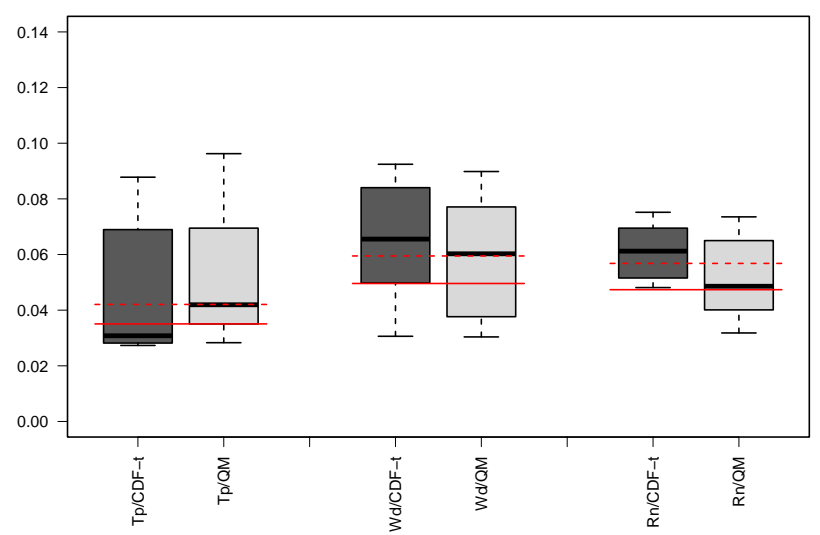

Fig. 5. Boxplots from the eight stations of KS scores computed between the CDF of the observations from the validation/projection period and the ERA40-downscaled CDFs, from both CDF-t and $\mathrm{QM}$, for temperature (Tp; two left-hand side boxplots), wind speed (Wd; two middle boxplots) and rainfall (Rn; two right-hand side boxplots) in winter.

and not representative of a real trend, they also impact localscale CDFs, then the disagreement between observations and downscaled CDFs will be high, as well as the KS scores. In other words, the evolutions or changes of the large-scale data that will drive the projection have more influence with CDF-t than with QM. For this reason, in order to avoid remaining too close to the observed CDFs, the CDF-t approach will be used in the following section to project future climate.

\section{Projections for future climate}

In this section, the CDFs of wind, temperature and rainfall are downscaled using the CDF-t probabilistic approach to examine whether changes in those distributions exhibit a high degree of sensitivity to the specific scenario experiment or GCM run. The scenarios used in the following are the B1 and A2 scenarios for two 20-yr periods: 2046-2065 and 2081-2100. We use $20 \mathrm{yr}$ of the control run between 1981 and 2000 to calibrate the CDF-t method for temperature and rainfall and a reduced 10-yr period (1991-2000) for wind downscaling. Compared to the method applied for present climate assessment, these extended calibration periods allow for a more accurate calibration of CDF-t. In the following, and for sake of legibility, only the figures displaying results for the A2 scenario will be shown.

\subsection{Temperature}

Using the GCM $925 \mathrm{hPa}$ temperature fields (which give the best results; see Sect. 3.1), Fig. 6 displays the KS values comparing the interpolated CDFs of surface temperature over 2046-2065 (a) and 2081-2100 (b) and the interpolated CDF over the 1991-2000 calibration period (left circles). It also 
displays the KS values comparing the downscaled CDFs over 2046-2065 (a) and 2081-2100 (b) and the downscaled $\mathrm{CDF}$ over the calibration period (right circles). The previous section (Fig. 3 and Table 3) has shown that for temperature, downscaled CDFs do not display significant differences with observed ones (to a lesser extent for Cannes). Over 2046-2065, the KS values produced by CDF-t are smaller and less spatially variable than those produced using interpolation, whereas over 2081-2100, they are similar. For both periods, all KS values are larger than the threshold values associated with the $80 \%$ and $90 \%$ confidence levels, thus, showing evidence of a significant change in surface temperature $\mathrm{CDF}$ in the scenario.

For a more thorough analysis, Table 4 displays the values of the $5 \%, 50 \%$ and $95 \%$ quantiles of temperature for the calibration period, and for 2045-2065 and 2081-2100 using the interpolation and CDF-t methods with the various CMIP3 models (IPSL, CNRM and ECHAM5) under the A2 scenario. This allows a more quantitative evaluation of the regional warming. One can first note a low sensitivity to the forcing GCM. The warming is slightly weaker when using the interpolation method, with hardly distinguishable warming over 2046-2065, whatever the GCM. The CDFs from interpolation are "shifted" by about $+2^{\circ}$. The warming is larger when using CDF-t, even over 2045-2065. One can also notice a larger impact on the $95 \%$ quantile of temperature. Indeed, for the A2 scenario, the $5 \%$ quantile increases by about $2^{\circ}$ between present and 2081-2100, whereas the $50 \%$ and $95 \%$ quantiles increase by about $4^{\circ}$ and $6^{\circ}$, respectively. For the B1 scenario (not shown), the relative spread is slightly larger between the GCMs and the warming is lower than for A2 scenario $\left(+0-2^{\circ}\right.$ for the $5 \%,+1-4^{\circ}$ for the $50 \%$ and $95 \%$ quantiles between present and 2081-2100).

In general, the results in summer and winter are very similar to those obtained over the whole year, despite a slightly larger spread in winter between downscaled CDFs with respect to the different forcing models. From Fig. 6 and Table 4 , it appears that all models produce similar results, whatever the season, and give results in agreement with Giorgi (2006).

Figure 7 displays the probability of having downscaled and interpolated surface temperature over 2081-2100 that exceeds the $95 \%$ quantile of the surface temperature calculated over the calibration period (1981-2000). Both CDF-t and interpolation produce more frequent warm events. For CDF-t, the $95 \%$ quantile over the calibration period corresponds approximately to the $80 \%$ quantile (on average for all stations) over 2081-2100. Compared to interpolation, CDF-t increases the warming trend and its spatial variability. One can also notice that IPSL GCM generally produces less extreme events than CNRM during summer and vice-versa during winter. The largest increase of temperature (trend and extremes) is obtained at Toulon, especially during winter.

\subsection{Wind speed}

Figure 8 is similar to Fig. 6, but for surface wind speed (which gives the best results; see Sect. 3.1). Wind speed distributions are very close in the calibration and projection periods, while temperature distributions are significantly different between the two periods. However, comparison of KS values with the KS thresholds shows evidence of a weak, but still significant difference. KS values increase for 20812100 , but not as strikingly as for temperature. Contrary to temperature, CDF-t downscaling produces larger KS values than the interpolation method, especially along the coastline (i.e., Toulon, Cannes). However, coastal stations should be analysed with care since they do not necessarily pass the KStest between the calibration and validation periods, especially at Cannes (see Sect. 3.1). The interpolated CDFs of surface wind speed show a decrease of mean wind speed, similar between scenario B1 and 2 (about $-1-2 \mathrm{~m} \mathrm{~s}^{-1}$ ) and whatever GCM large-scale surface wind speed used as input (Table 4). The effect is dominated by the winter trend. The wind decrease trend is consistent with Najac et al. $(2009,2010)$, Michelangeli et al. (2009) and Vautard et al. (2010).

The evolution of extreme wind speed is less evident than for temperature. With interpolation, the weak decrease of the median wind speed is associated with a decrease of wind extremes (except for Cannes and Aix) as suggested in Fig. 9. This figure shows that, at most stations, downscaling and interpolation produce fewer extreme wind speed events compared to the calibration period. Table 4 gives a quantitative estimate of the wind decrease, which is similar to the median decrease, i.e., about $-1-2 \mathrm{~m} \mathrm{~s}^{-1}$, even if the downscaling method tends to increase the occurrence of these events in relation to the interpolation method. These results are also consistent with Najac et al. (2009, 2010); Michelangeli et al. (2009); Vautard et al. (2010). With CDF-t, the situation is more variable. In some stations, the occurrence probability of extreme wind events increases, especially during summer, whereas it is nearly constant during winter (except a possible increase in Toulon). Averaging over the seven stations does not allow us to conclude on the evolution of the wind speed distribution CDFs under the two scenarios.

\subsection{Rainfall}

Using interpolation with processing 1 , the rainfall occurrence over the calibration and the 2081-2100 periods is sensitive to the GCM (about $30 \%$ difference between the minimum and maximum rainfall occurrence produced by ECHAM5 and CNRM GCMs). The rainfall occurrence decreases between the calibration and the 2081-2100 periods by about $9 \%$ under A2 scenario (Table 5). This decrease is slightly larger during summer than winter (not shown). Using CDF$t$, rainfall occurrence over $2081-2100$ is even lower $(-10 \%$ relative to the interpolated rainfall over 2081-2100). Rainfall downscaling with processing 2 produce lower rainfall 


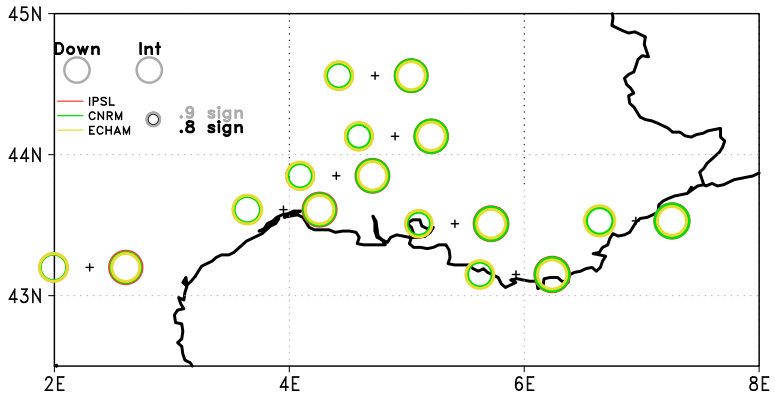

(a) Temperature, 2046-2065

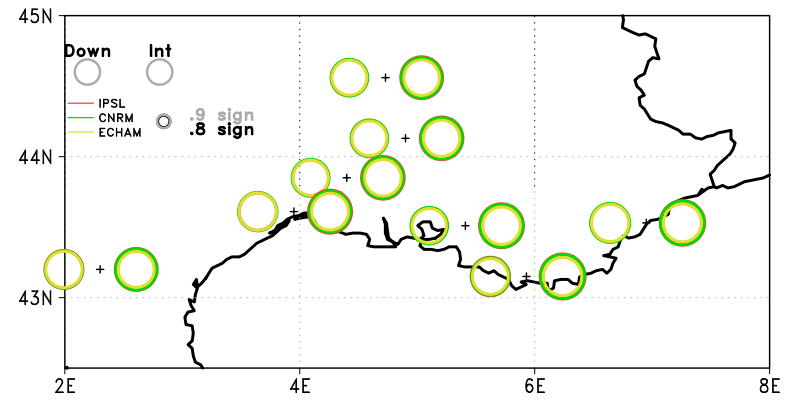

(b) Temperature, 2081-2100

Fig. 6. Circle areas are proportional to the KS scores computed over the whole year (i.e., no seasonal discrimination) between the CDFs of temperature from each GCM during the validation period and those during the two future periods (2046-2065 on the left and 2081-2100 on the right) under the A2 scenario. Crosses indicate the location of each station. The CDFs are computed using either the interpolation (right side with respect to the cross) or the downscaling method (left side with respect to the cross). Black and grey circles display the $80 \%$ and $90 \%$ confidence levels (i.e., $\alpha=0.2$ and 0.1 ) of the $\mathrm{KS}$ scores.

Table 4. Values (averaged over the 7 stations) of the 5\%, 50\% and $95 \%$ quantiles for temperature (in degrees Celsius) and $50 \%$ and $95 \%$ for wind speed (in $\mathrm{m} \mathrm{s}^{-1}$ ) and precipitation (in mm) for the calibration period, and for the two future time slices (2045-2065 and 2081-2100) using the interpolation (Int) and CDF-t (Down) methods with the various CMIP3 models (IPSL, CNRM and ECHAM5) for scenarios A2.

\begin{tabular}{|c|c|c|c|c|c|c|c|c|}
\hline & & \multirow{2}{*}{$\begin{array}{c}\text { Calibration } \\
1981-2000\end{array}$} & \multicolumn{2}{|c|}{ IPSL } & \multicolumn{2}{|c|}{ CNRM } & \multicolumn{2}{|c|}{ ECHAM5 } \\
\hline & & & $2045-2065$ & $2081-2100$ & $2045-2065$ & $2081-2100$ & $2045-2065$ & $2081-2100$ \\
\hline \multirow{3}{*}{ Int } & Temperature & $3 / 13 / 26$ & $5 / 14 / 25$ & $7 / 16 / 27$ & $5 / 12 / 24$ & $7 / 13 / 28$ & $5 / 13 / 25$ & $7 / 15 / 28$ \\
\hline & Temperature Winter & $0 / 8 / 14$ & $3 / 9 / 14$ & $5 / 11 / 16$ & $4 / 8 / 12$ & $6 / 9 / 14$ & $4 / 9 / 13$ & $5 / 10 / 15$ \\
\hline & Temperature Summer & $12 / 20 / 28$ & $13 / 21 / 26$ & $15 / 23 / 28$ & $11 / 20 / 25$ & $13 / 23 / 29$ & $13 / 20 / 26$ & $14 / 23 / 30$ \\
\hline \multirow{3}{*}{ Down } & Temperature & $3 / 13 / 26$ & $5 / 15 / 30$ & $7 / 18 / 32$ & $5 / 15 / 29$ & $6 / 17 / 33$ & $6 / 15 / 29$ & $7 / 17 / 33$ \\
\hline & Temperature Winter & $0 / 8 / 14$ & $3 / 10 / 16$ & $5 / 12 / 18$ & $3 / 9 / 16$ & $4 / 10 / 18$ & $4 / 10 / 16$ & $5 / 11 / 19$ \\
\hline & Temperature Summer & $12 / 20 / 28$ & $14 / 23 / 32$ & $17 / 25 / 34$ & $15 / 23 / 31$ & $17 / 26 / 35$ & $14 / 23 / 31$ & $14 / 25 / 36$ \\
\hline \multirow{3}{*}{ Int } & Wind speed & $2.4 / 6.4$ & $2.1 / 4.3$ & $2 / 4.3$ & $2.1 / 4.6$ & $2 / 4.6$ & $2.9 / 6$ & $2.8 / 6$ \\
\hline & Wind speed Winter & $2.5 / 6.9$ & $2.6 / 4.8$ & $2.5 / 4.8$ & $2.8 / 5.1$ & $2.8 / 5$ & $3.5 / 6.5$ & $3.4 / 6.5$ \\
\hline & Wind speed Summer & $2.3 / 5.8$ & $1.6 / 3.4$ & $1.6 / 3.4$ & $1.5 / 3.5$ & $1.3 / 3.3$ & $2.4 / 5.1$ & $2.3 / 5$ \\
\hline \multirow{3}{*}{ Down } & Wind & $2.4 / 6.4$ & $2.3 / 6.4$ & $2.3 / 6.2$ & $2.3 / 6.4$ & $2.3 / 6.3$ & $2.3 / 6.4$ & $2.2 / 6.4$ \\
\hline & Wind speed Winter & $2.5 / 6.9$ & $2.4 / 7.1$ & $2.3 / 6.8$ & $2.3 / 6.9$ & $2.3 / 6.7$ & $2.5 / 7.1$ & $2.3 / 6.9$ \\
\hline & Wind speed Summer & $2.3 / 5.8$ & $2.2 / 5.8$ & $2.2 / 5.7$ & $2.3 / 6$ & $2.2 / 6$ & $2.2 / 5.6$ & $2.1 / 5.7$ \\
\hline \multirow{3}{*}{ Int } & Rain (processing 1) & $1.4 / 12.9$ & $0.7 / 7$ & $0.7 / 7.4$ & $1.5 / 6.6$ & $1.2 / 6.5$ & $0.2 / 8.6$ & $0.1 / 8$ \\
\hline & Rain Winter (processing 1) & $1.4 / 12$ & $1.2 / 8.4$ & $1.2 / 9$ & $2 / 7.2$ & $1.9 / 7.3$ & $0.8 / 11.1$ & $0.6 / 10.8$ \\
\hline & Rain Summer (processing 1) & $1.3 / 13.1$ & $0.4 / 4.8$ & $0.4 / 5.2$ & $1.2 / 5$ & $0.8 / 4.3$ & $0.0 / 4.3$ & $0.0 / 3$ \\
\hline \multirow{3}{*}{ Down } & Rain (processing 1) & $1.4 / 12.9$ & $1.4 / 13.5$ & $1.4 / 15.7$ & $1.4 / 13$ & $1.3 / 13.4$ & $1.4 / 14.2$ & $1.4 / 13.2$ \\
\hline & Rain Winter (processing 1) & $1.4 / 12$ & $1.3 / 13$ & $1.3 / 14.4$ & $1.2 / 12.2$ & $1.1 / 12.9$ & $1.3 / 14.3$ & $1.2 / 13.6$ \\
\hline & Rain Summer (processing 1) & $1.3 / 13.1$ & $1.3 / 13.2$ & $0.8 / 4.3$ & $1.3 / 12.5$ & $1.2 / 11.7$ & $1.5 / 13.5$ & $1.3 / 9.8$ \\
\hline \multirow{3}{*}{ Int } & Rain (processing 2) & $1.4 / 12.9$ & $5.5 / 12.4$ & $5.8 / 14.9$ & $5.5 / 11.6$ & $5.4 / 11.9$ & $6.3 / 19.6$ & $5.6 / 18.9$ \\
\hline & Rain Winter (processing 2) & $1.4 / 12$ & $7 / 13.9$ & $7.3 / 15.9$ & $6.2 / 11.4$ & $6.4 / 12.2$ & $8.6 / 21.3$ & $8.5 / 20.6$ \\
\hline & Rain Summer (processing 2) & $1.3 / 13.1$ & $3.9 / 9.6$ & $4.1 / 9.6$ & $4 / 9.6$ & $3.5 / 9.1$ & $1.5 / 13.5$ & $1.8 / 9.9$ \\
\hline \multirow{3}{*}{ Down } & Rain (processing 2) & $1.4 / 12.9$ & $1.4 / 13.4$ & $1.4 / 15.1$ & $1.4 / 13$ & $1.3 / 13.4$ & $1.4 / 14.2$ & $1.4 / 13.3$ \\
\hline & Rain Winter (processing 2) & $1.4 / 12$ & $1.4 / 13$ & $1.3 / 14.3$ & $1.2 / 12.2$ & $1.1 / 12.9$ & $1.3 / 14.3$ & $1.2 / 13.6$ \\
\hline & Rain Summer (processing 2) & $1.3 / 13.1$ & $1.3 / 13.2$ & $1.3 / 15.8$ & $1.3 / 12.5$ & $1.2 / 11.7$ & $1.5 / 13.5$ & $1.3 / 9.8$ \\
\hline
\end{tabular}




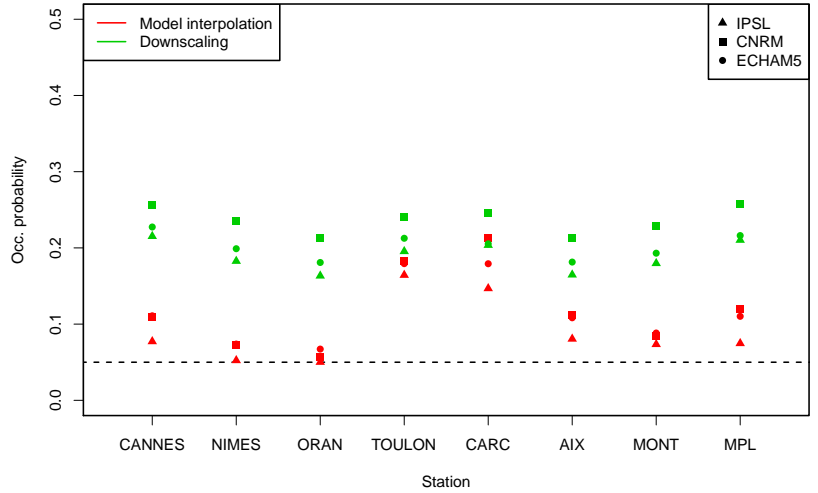

(a) Temperature (whole year), 2081-2100

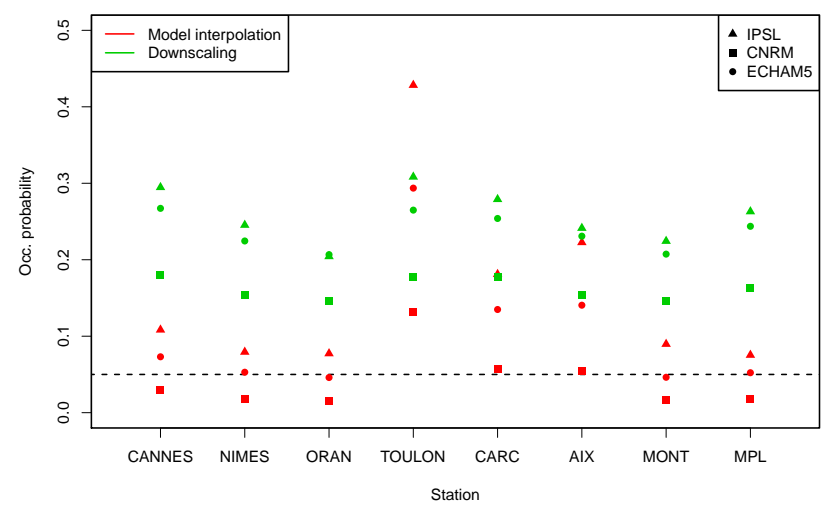

(b) Temperature, Winter, 2081-2100

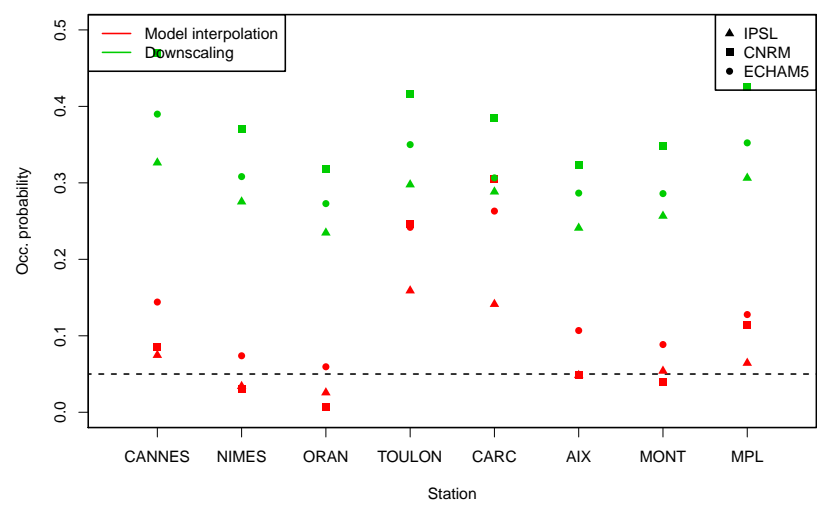

(c) Temperature, Summer, 2081-2100

Fig. 7. Probability of having a temperature during the 2081-2100 period that exceeds the $95 \%$ quantile of temperature over the calibration period (1981-2000) for the whole year (a), winter (b) and summer (c).

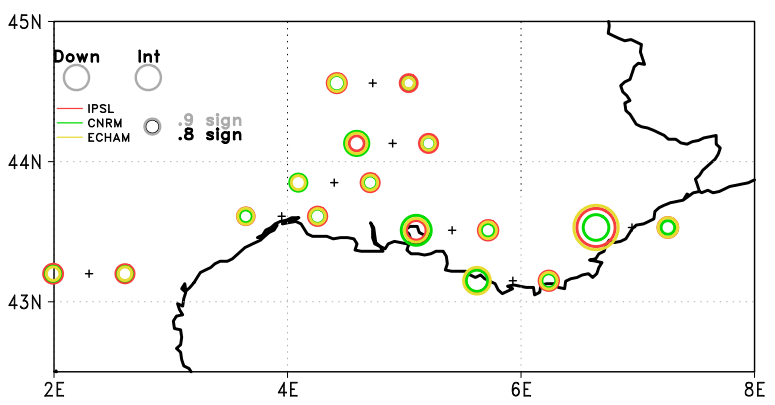

(a) Wind speed (whole year), 2046-2065

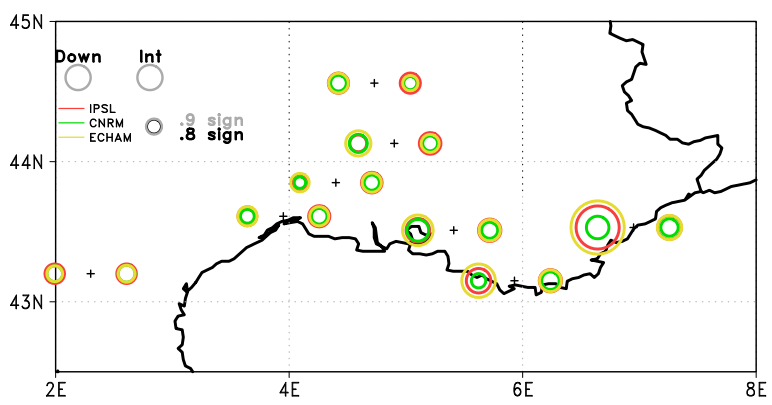

(b) Wind speed, 2081-2100

Fig. 8. Same as Fig. 6 for wind speed.

occurrence as discussed in Sect. 3.1. The occurrence of rainfall downscaled with CDF-t decreases between the calibration and the 2081-2100 periods (about $20 \%$ under A2 scenario for IPSL and CNRM GCMs and $40 \%$ with ECHAM5 GCM; Table 5).
Figure 10a shows that rainfall CDF (using processing 1) significantly changes between present and the 2046-2065 period (Fig. 10a). This is associated with an increase of the heavy rainfall events (Table 4). Over 2081-2100 (Fig. 10b), the KS scores keep increasing. A contrast appears between IPSL, which produces systematically the lowest KS scores, 


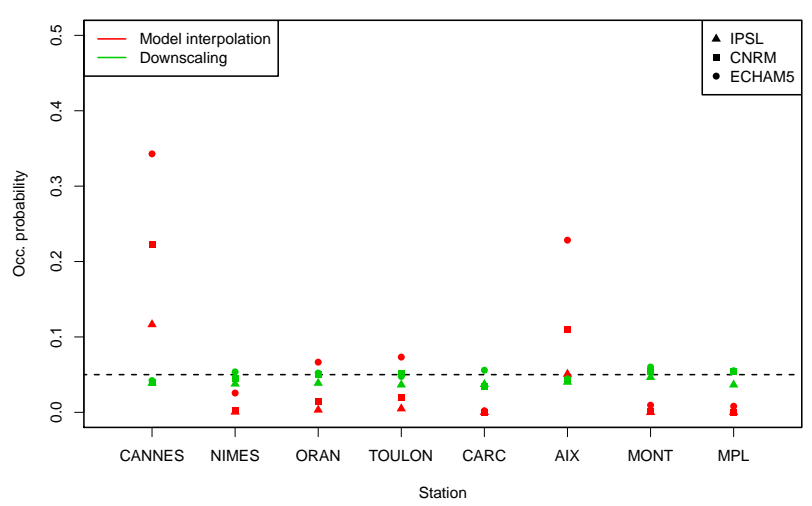

(a) Wind speed, 2081-2100

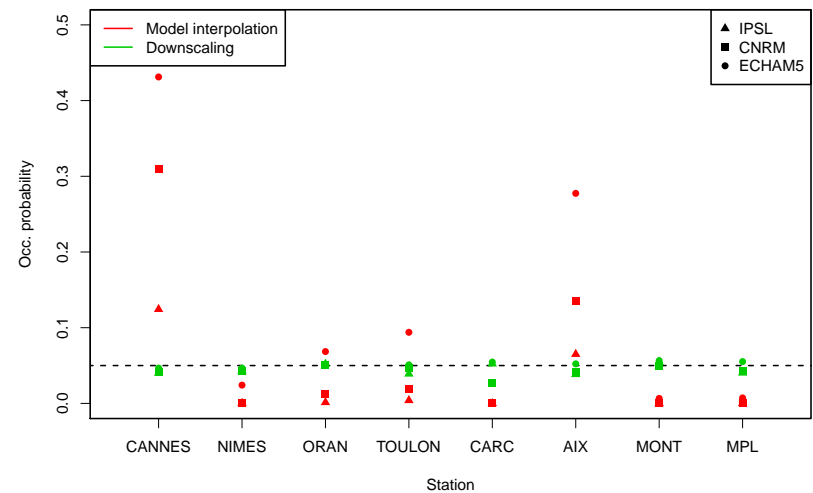

(b) Wind speed, Winter, 2081-2100

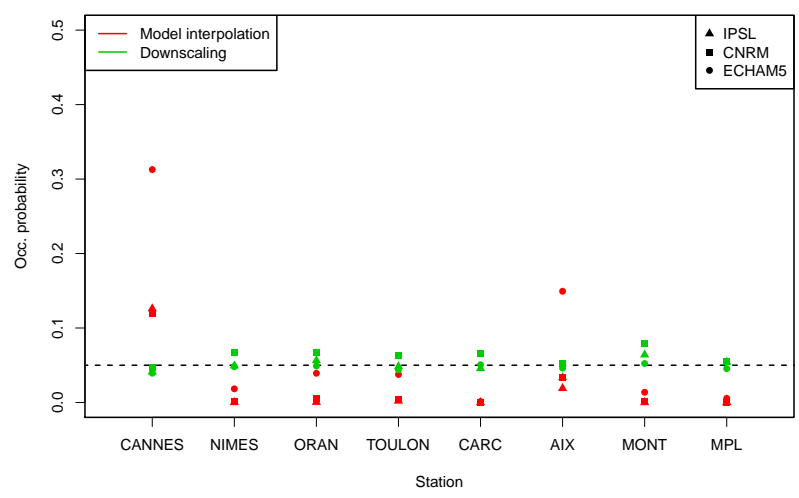

(c) Wind speed, Summer, 2081-2100

Fig. 9. Same figure as Fig. 7 for the strongest wind speed.

Table 5. Rainfall occurrence obtained from interpolated GCM rainfall over the 1981-2000 calibration period (columns 2 and 4 ) and the 2081-2100 projection period with the A2 scenario. Columns 2 and 3, and 4 and 5 correspond to processing 1 (non-zero precipitation) and processing 2 (threshold precipitation), respectively. The values in brackets correspond to probabilities computed from CDF-t downscaling.

\begin{tabular}{lcccc}
\hline \multirow{2}{*}{ Model } & \multicolumn{2}{c}{ Processing 1 } & \multicolumn{2}{c}{ Processing 2 } \\
& Calibration period & Projection period & Calibration period & Projection period \\
\hline IPSL int (down) & 0.79 & $0.70(0.64)$ & 0.15 & $0.15(0.12)$ \\
CNRM int (down) & 0.98 & $0.92(0.81)$ & 0.15 & $0.15(0.12)$ \\
ECHAM int (down) & 0.67 & $0.51(0.46)$ & 0.15 & $0.15(0.09)$ \\
\hline
\end{tabular}

and CNRM. Note that, as mentioned in Sect. 3.1, the magnitude and the spatial variability of the KS values using the interpolation method with rainfall threshold depends on the length of the dataset which can vary from one station to another after rainfall thresholding. In this figure, we use the average of the significance KS scores.

Figure 11 is similar to Fig. 10, but for daily rainfall with processing 2 . The KS values, even though significant, remain close to their threshold values. This is partly due to the truncation induced by the threshold which reduces the data length and arbitrary increases the KS score for the low pre- cipitating events. The rainfall evolution for the 2081-2100 period is more uncertain than for temperature. The interpolation displays a larger spread than CDF-t with respect to the GCMs used as inputs. As for temperature, CDF-t tends to decrease the difference with the calibration period. Although interpolated ECHAM5 and CNRM GCM rainfall produce the largest $\mathrm{KS}$ values at most stations, CDF-t gives results relatively similar for all stations.

Table 5 shows that, on average, the interpolation method displays a decrease of precipitation when no threshold is applied (processing 1), whereas no trend is observed with a 


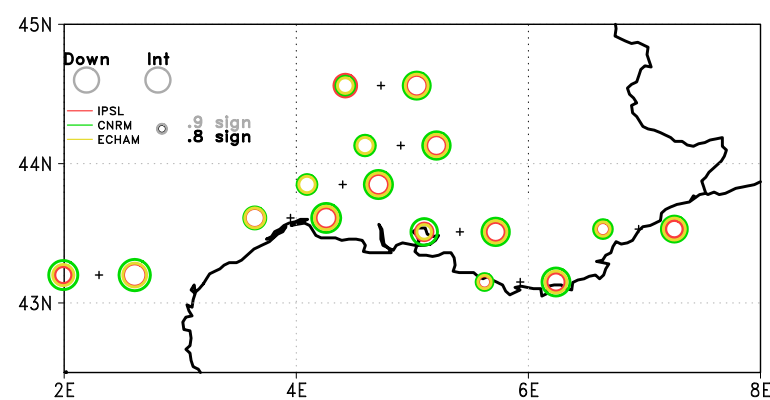

(a) rainfall, 2046-2065

Fig. 10. Same as Fig. 6 but for daily rainfall with processing 1 .

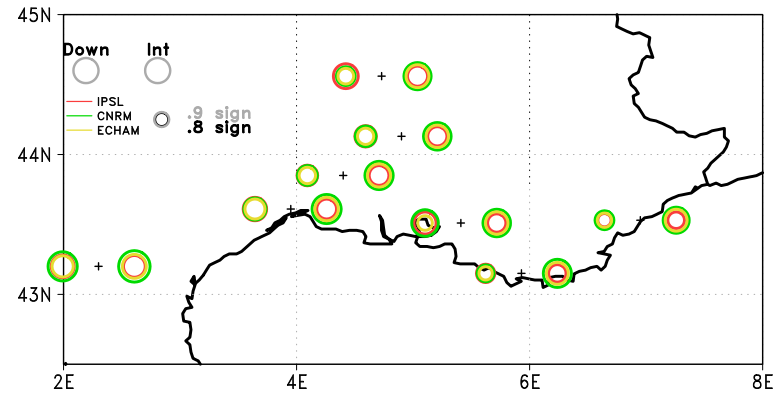

(a) rainfall, 2046-2065

Fig. 11. Same as Fig. 6, but for daily rainfall with processing 2 .

threshold (processing 2). CDF-t displays less inter-model variability and a decrease in rainfall occurrence whatever the method used (between -20 and $-40 \%$ rainfall occurrence between present and 2081-2100).

The evolution of extremes is also less evident for rainfall than for temperature (Fig. 12). For extreme rainfall without threshold, the evolution is weak with probabilities of exceeding the $95 \%$ quantile of the observed rainfall only slightly larger than 5\% with CDF-t over 2081-2100. Conversely, the interpolation method with processing 1 gives much lower occurrence of extreme rainfall. With processing 2 , the evolution is more consistent between interpolation and CDF-t downscaling with an increase of extreme rainfall (occurrence exceeding the $95 \%$ quantile of the observed rainfall quasi systematically larger than $5 \%$ ). However, CDF-t produces less increase of extreme rainfall occurrence (only slightly larger than 5\%) than bi-linear interpolation. Indeed, the very large occurrence obtained with bi-linear interpolation is caused by rainfall thresholding which removes the low rainfall events. The extreme rainfall occurrence obtained with CDF-t is very similar with and without rainfall thresholding.

Finally, with CDF-t and interpolation with processing 2, the $95 \%$ quantiles displayed in Table 4 show that for all GCMs and scenarios, the extreme events increase, which is also visible in Fig. 12, especially with the CNRM GCM. This is in agreement with Giorgi (2006).

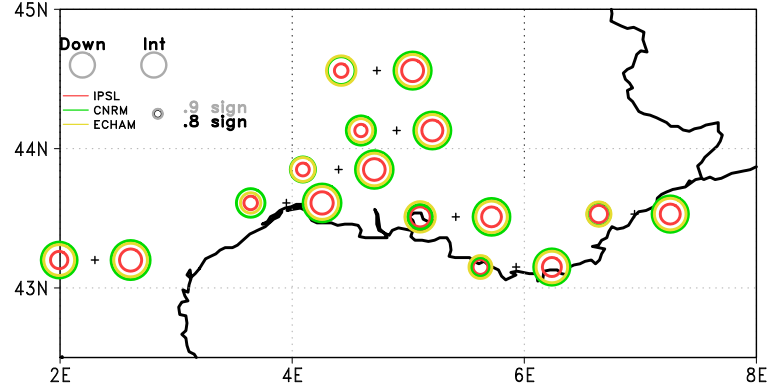

(b) rainfall, 2081-2100

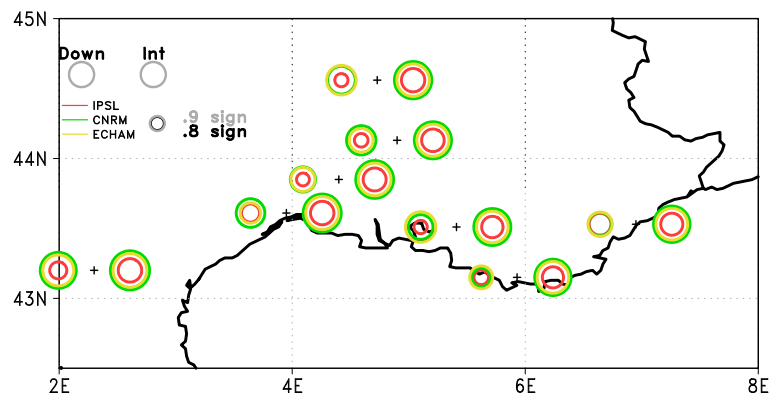

(b) rainfall, 2081-2100

\section{Conclusions}

A new probabilistic downscaling method, named "Cumulative Distribution Function - transform" (or CDF-t), has been developed by Michelangeli et al. (2009) for wind downscaling and renewable energy issues. In this article, CDF-t was also adapted and applied for temperature and rainfall. The specific case of rainfall is delicate since, so far, only the positive precipitation can be downscaled and not the full rainfall CDF which would include also the dry spell periods. Compared to other methods, like Quantiles-mapping (Panofsky and Brier, 1958; Haddad and Rosenfeld, 1997), CDF-t has a fundamental advantage that it takes into account the evolution of the large-scale distribution and then can be used outside the range of the data (wind speed, temperature and rainfall) of the calibration period. This is a key element for selecting such a method when applied in the context of local projections of climate change.

In this study, a thorough analysis of the uncertainty associated with statistical downscaling and bi-linear interpolation of large-scale wind speed, temperature and rainfall from reanalyses (ERA-40) and historical GCM simulations, has been conducted and quantified in terms of KolmogorovSmirnov scores. Compared to interpolation which can be seen here as a reference method (widely used for CMIP3 data analysis for IPCC AR4; e.g., Giorgi, 2006), CDF-t produces 


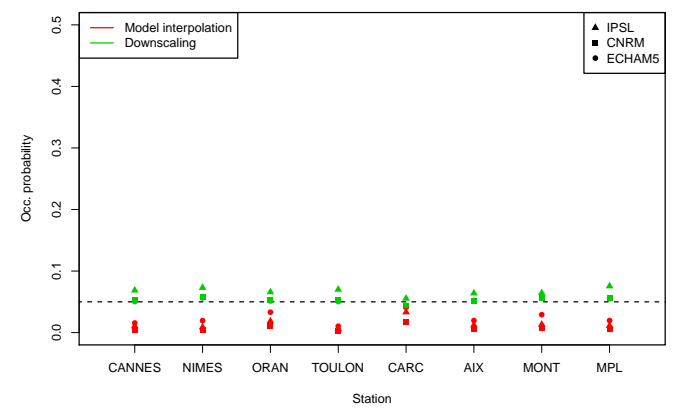

(a) Rain (processing 1), 2081-2100

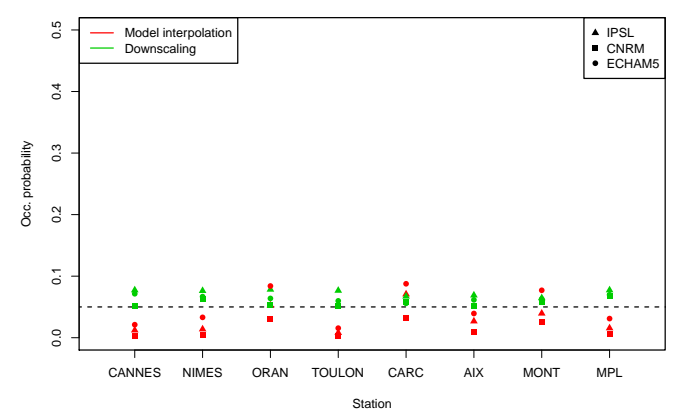

(c) Rain (processing 1), Winter, 2081-2100

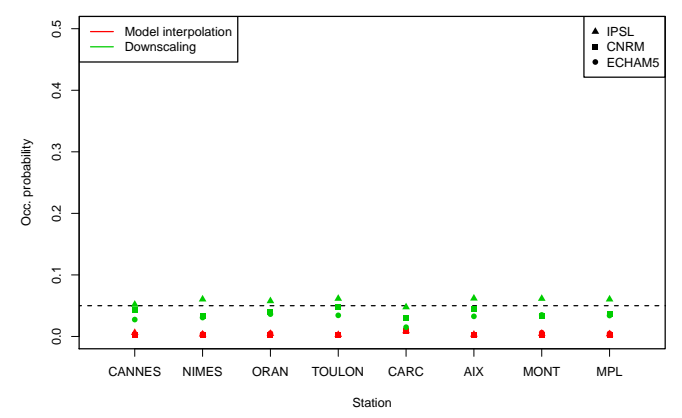

(e) Rain (processing 1), Summer, 2081-2100

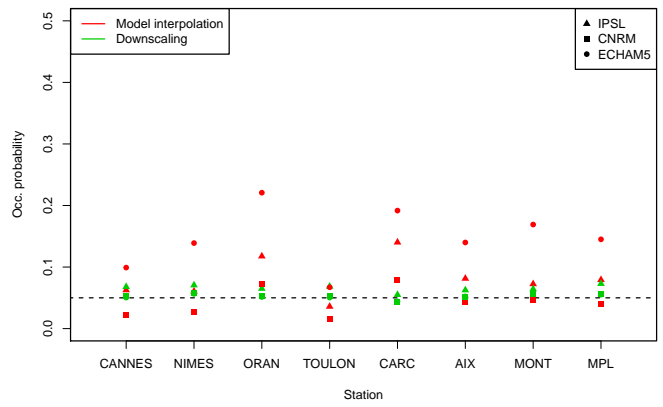

(b) Rain (processing 2), 2081-2100

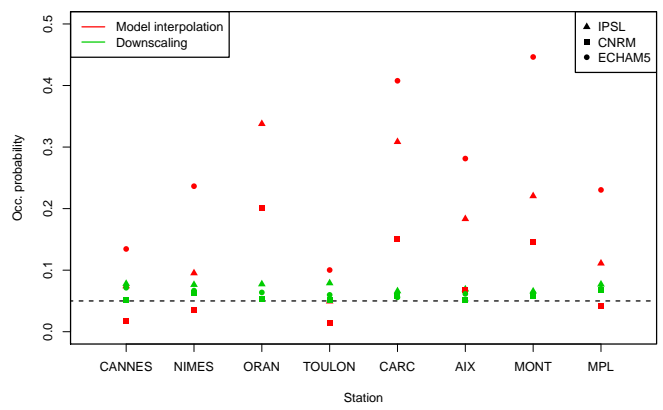

(d) Rain (processing 2), Winter, 2081-2100

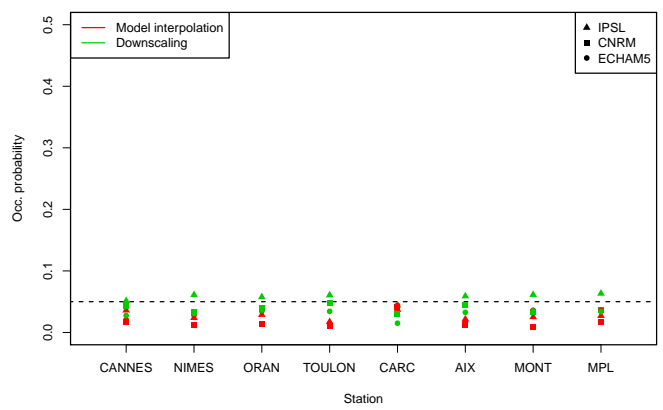

(f) Rain (processing 2), Summer, 2081-2100

Fig. 12. Same figure as Fig. 7 for extreme rainfall events without (left) or with threshold (right) over 2081-2100 for the whole year (a, b), winter (c, d) and summer (e, f).

much more accurate and reliable local wind speed, temperature and rainfall. This advocates for the use of downscaling techniques to provide reliable information on regional climate. However, the reliability of the downscaling may differ from one station to another. Especially Cannes displays very poor performance whatever the downscaling method used for wind speed, temperature and rainfall. CDF-t performances are not sensitive to the model performance but it is sensitive to the variability and trend of the driving large-scale fields (ERA-40 reanalysis or CMIP3 control runs) which can perform better or worse depending on the variable but also on the season. No GCM can be identified as the "best per- former". More surprisingly, the ERA-40 reanalysis does not necessarily and systematically produce the best downscaled $\mathrm{CDF}$, even though it still produces most often the best CDFs.

CDF-t was then applied to IPSL, CNRM and ECHAM5 climate simulations of the 21 st century under B1 and A2 scenarios. As expected, the most striking trend is obtained for temperature (median and extremes), whereas for wind speed and rainfall, the evolution of the distributions is weaker and more uncertain. Mean surface wind speed and wind extremes seem to decrease in most locations, whereas the mean rainfall value decreases while the extremes seem to slightly increase. This is consistent with previous studies but this study, 
by quantifying the uncertainty, reveals the need to develop improved methodologies in statistical and dynamical downscaling, to reduce the uncertainty and produce more robust trends.

Acknowledgements. We are thankful to E. Martin for providing the Safran reanalysis, to E. Flaounas for reviewing the manuscript and to the MEDUP group for fruitful discussion. This research has received funding from the ANR-MEDUP and ADEME (Agence de l'Environnement et de la Maîtrise de l'Energie) through contract ADEME 0705C0038, and from GIS "Climat Environnement Société" through the REGYNA project.

Edited by: V. Ducrocq

Reviewed by: two anonymous referees

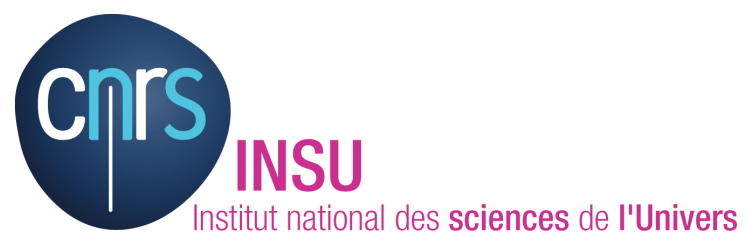

The publication of this article is financed by CNRS-INSU.

\section{References}

Alpert, P., Neeman, B. U., and Shay-El, Y.: Climatological analysis of Mediterranean cyclones using ECMWF Data, Tellus, 42A, 65-77, 1990.

Boé, J., Terray, L., Habets, F., and Martin, E.: A simple statistical-dynamical downscaling scheme based on weather types and conditional resampling, 111, D23106, $20 \mathrm{pp}$., doi:10.1029/2005JD006889, 2006.

Busuioc, A., Tomozeiu, R., and Cacciamani, C.: Statistical downscaling model based on canonical correlation analysis for winter extreme precipitation events in the Emilia-Romania region, Int. J. Climatol., 28, 449-464, 2008.

Cannon, A. J. and Whitfield, P. H.: Downscaling recent streamflow conditions in British Columbia, Canada using ensemble neural network models, J. Hydrol., 259, 136-151, 2002.

Darling, D. A.: The Kolmogorov-Smirnov, Cramer-von Mises Tests, Ann. Math. Statist., 28, 823-838, 1957.

Déqué, M.: Frequency of precipitation and temperature extremes over France in an anthropogenic scenario: model results and statistical correction according to observed values, Global Planet. Change, 57, 16-26, 2007.

Déqué, M., Jones, R. G., Wild, M., Giorgi, F., Christensen, J. H., Hassell, D. C., Vidale, P. L., Rockel., B., Jacob, D., Kjellstrom, E., de Castro, M., Kucharski, F., and van den Hurk, B.: Global high resolution versus Limited Area Model scenarios over Europe: results from the PRUDENCE project, Clim. Dynam., 25, 653-670, 2005.

Drobinski, P., Bastin, S., Guénard, V., Caccia, J. L., Dabas, A. M., Delville, P., Protat, A., Reitebuch, O., and Werner, C.: Summer mistral at the exit of the Rhône valley, Q. J. R. Meteorol. Soc., 131, 353-375, 2005.
Drobinski, P., Flamant, C., Dusek, J., Flamant, P. H., and Pelon, $\mathrm{J}$.: Observational evidence and modeling of an internal hydraulic jump at the atmospheric boundary layer top during a tramontane event, Bound.-Lay. Meteorol., 98, 497-515, 2001.

Ducrocq, V., Ricard, D., Lafore, J. P., and Orain, F.: Storm-scale numerical rainfall prediction for five precipitating events over France: on the importance of the initial humidity field, Weather Forecast., 17, 1236-1256, 2002.

Ducrocq, V., Nuissier, O., Ricard, D., Lebeaupin, C., and Thouvenin, T.: A numerical study of three catastrophic precipitating events over Western Mediterranean region (Southern France). Part II: Mesoscale triggering and stationarity factors, Q. J. R. Meteorol. Soc., 134, 111-130, 2008.

Durand, Y., Brun, E., Mérindol, L., Guyomarc'h, G., Lesaffre, B., and Martin, E.: A meteorological estimation of relevant parameters for snow models, Ann. Glaciol., 18, 65-71, 1993.

Durand, Y., Giraud, G., Brun, E., Mérindol, L., and Martin, E.: A computer-based system simulating snowpack structure as a tool for regional avalanche forecasting, J. Glaciol., 45, 469-484, 1999.

Durand, Y., Laternser, M., Giraud, G., Etchevers, P., Lesaffre, B., and Mérindol, L.: Reanalysis of 44 years of climate in the French Alps (1958-2002): methodology, model validation, climatology and trends for air temperature and precipitation, J. Appl. Meteorol. Climatol., 48, 429-449, 2009.

Gao, X., Pal, J. S., and Giorgi, F.: Projected changes in mean and extreme precipitation over the Mediterranean region from high resolution double nested RCM simulation, Geophys. Res. Lett., 33, L03706, doi:10.1029/2005GL024954, 2006.

Gibelin, A.-L. and Déqué, M.: Anthropogenic climate change over the Mediterranean region simulated by a global variable resolution model, Clim. Dynam., 20, 327-339, 2003.

Giorgi, F.: Climate change hot-spots, Geophys. Res. Lett., 33, L08707, doi:10.1029/2006GL025734, 2006.

Giorgi, F. and Bi, X.: Updated regional precipitation and temperature changes for the 21 st century from ensembles of recent AOGCM simulations, Geophys. Res. Lett., 32, L21715, doi:10.1029/2005GL024288, 2005.

Goubanova, K., Echevin, V., Dewitte, B., Codron, F., Takahashi, K., Terray, P., and Vrac, M.:Statistical downscaling of sea-surface wind over the Peru-Chile upwelling region: diagnosing the impact of climate change from the IPSL-CM4 model, Clim. Dynam., 36, 1365-1378, doi:10.1007/s00382-010-0824-0, 2010.

Guénard, V., Drobinski, P., Caccia, J. L., Tedeschi, G., and Currier, P.: Dynamics of the MAP IOP-15 severe mistral event: observations and high-resolution numerical simulations, Q. J. R. Meteorol. Soc., 132, 757-778, 2006.

Guénard, V., Drobinski, P., Caccia, J. L., Campistron, B., and Bénech, B.: An observational study of the mesoscale mistral dynamics, Bound.-Lay. Meteorol., 115, 263-288, 2005.

Haddad, Z. S. and Rosenfeld, D.: Optimality of empirical Z-R relations, Q. J. R. Meteorol. Soc., 123, 1283-1293, 1997.

Haylock, M. R., Cawley, G. C., Harpham, C., Wilby, R. L., and Goodess, C. M.: Downscaling heavy precipitation over the United Kingdom: a comparison of dynamical and statistical methods and their future scenarios, Int. J. Climatol., 26, 13971415, 2006.

Huet, P., Martin, X., Prime, J. L., Foin, P., Laurin, C., and Cannard, P.: Retour d'expérience des crues de Septembre 2002 dans les 
départements du Gard, de l'Hérault, du Vaucluse, des Bouches du Rhone, de l'Ardeche et de la Drome, Rapport de l'Inspection Générale de l'Environnement, Ministere de l'écologie et du développement durable, 133 pp., 2003.

Huth, R.: Disaggregating climatic trends by classification of circulation patterns, Int. J. Climatol., 21, 135-153, 2001.

Huth, R.: Statistical downscaling of daily temperature in central Europe, J. Climate, 15, 1731-1742, 2002.

Huth, R., Kliegrová, S., and Metelka, L.: Non-linearity in statistical downscaling: does it bring an improvement for daily temperature in Europe?, Int. J. Climatol., 28, 465-477, 2008.

Köpen, W.: Das geographishe system der klimate, in:Handbuch der Klimatologie 3. Gebrueder Borntraeger, edited by: Köpen and Geiger, Berlin, 46 pp., 1936.

Lebeaupin Brossier, C. and Drobinski, P.: Numerical highresolution air-sea coupling over the Gulf of Lions during two tramontane/mistral events, J. Geophys. Res., 114, D10110, doi:10.1029/2008JD011601, 2009.

Lebeaupin, C., Ducrocq, V., and Giordani, H.: Sensitivity of torrential rain events to the sea surface temperature based on highresolution numerical forecasts, J. Geophys. Res., 111, D12110, doi:10.1029/2005JD006541, 2006.

Le Moigne, P.: Description de l'Analyse des Champs de Surface sur la France par le Système SAFRAN (Description of the Analysis of Near-Surface Atmospheric Fields over France with Safran System), CNRM/GAME report, 77, available from CNRM/GAME, Météo-France/CNRS, Toulouse, France, 2002 (in French).

Li, H., Sheffield, J., and Wood, E. F.: Bias correction of monthly precipitation and temperature fields from Intergouvernmental Panel on climate change AR4 models using equidistant quantile matching, J. Geophys. Res., 115, D10101, doi:10.1029/2009JD012882, 2010.

Maraun, D., Wetterhall, F., Ireson, A. M., Chandler, R. E., Kendon, E. J., Widmann, M., Brienen, S., Rust, H. W., Sauter, T., Themeß1, M., Venema, V. K. C.,Chun, K. P., Goodess, C. M., Jones, R. G., Onof, C., Vrac, M., and Thiele-Eich, I.: Precipitation downscaling under climate change. Recent developments to bridge the gap between dynamical models and the end user, Rev. Geophys., 48, RG3003, doi:10.1029/2009RG000314, 2010.

Maurer, E. P. and Hidalgo, H. G.: Utility of daily vs. monthly large-scale climate data: an intercomparison of two statistical downscaling methods, Hydrol. Earth Syst. Sci., 12, 551-563, doi:10.5194/hess-12-551-2008, 2008.

Michelangeli, P. A., Vrac, M., and Loukos, H.: Probabilistic downscaling approaches: application to wind cumulative distribution functions, Geophys. Res. Lett., 36, L11708, doi:10.1029/2009GL038401, 2009.

Moisselin, J. M., Schneider, M., Canellas, C., and Mestre, O.: Les changements climatiques en France au XX siècle: études des longues séries homogénéisées de données de température et de précipitations, La Météorologie, 54, 33-42, 2002.

Najac, J., Boé, J., and Terray, L.: A multi-model ensemble approach for assessment of climate change impact on surface winds in France, Clim. Dynam., 32, 615-634, 2009.

Najac, J., Lac, C., and Terray, L.: Impact of climate change on surface winds in France using a statistical-dynamical downscaling method with mesoscale modeling, Int. J. Climatol., doi:10.1002/joc.2075, 2010.
Panofsky, H. A. and Brier, G. W.: Some applications of statistics to meteorology, Penn. State Univ. Press, University Park, 1958.

Petterssen, S.: Weather analysis and forecasting, McGraw-Hill, New-York, 428 pp., 1956.

Quereda Sala, J., Gilolcina, A., Perez Cuevas, A., Olcina Cantos, J., Rico Amoros, A., and Monton Chiva, Q. R.: Climatic warming in the Spanish Mediterranean: natural trend or urban effect (Cicyt Project, National Climate Plan), Climatic Change, 46, 473-483, 2000.

Quintana-Seguí, P., Le Moigne, P., Durand, Y., Martin, E., Habets, F., Baillon, M., Canellas, C., Franchistéguy, L., and Morel, S.: Analysis of near surface atmospheric variables: validation of the SAFRAN analysis over France, J. Appl. Meteorol. Climatol., 47, 92-107, 2008.

Quintana-Seguí, P., Habets, F., and Martin, E.: Comparison of past and future Mediterranean high and low extremes of precipitation and river flow projected using different statistical downscaling methods, Nat. Hazards Earth Syst. Sci., 11, 1411-1432, doi:10.5194/nhess-11-1411-2011, 2011.

Sailor, D. J. and Xiangshang, L.: A semi-empirical downscaling approach for predicting regional temperature impacts associated with climatic change, J. Clim., 12, 103-114, 1999.

Salameh, T., Drobinski, P., Vrac, M., and Naveau, P.: Statistical downscaling of near-surface wind over complex terrain in Southern France, Metetorol. Atmos. Phys., 103, 243-256, 2009.

Salameh, T., Drobinski, P., Menut, L., Bessagnet, B., Flamant, C., Hodzic, A., and Vautard, R.: Aerosol distribution over the western Mediterranean basin during a Tramontane/Mistral event, Ann. Geophys., 25, 2271-2291, doi:10.5194/angeo-25-22712007, 2007.

Schnur, R. and Lettenmaier, D.: A case study of statistical downscaling in Australia using weather classification by recursive partitioning, J. Hydrol., 212-213, 362-379, 1998.

Semenov, M. A., Brooks, R. J., Barrow, E. M., and Richardson, C. W.: Comparison of the WGEN and the LARS-WG stochastic weather generators in diverse climates, Clim. Res., 10, 95-107, 1998.

Simmons, A. J. and Gibson, J. K.: The ERA-40 project plan, ERA40 project Rep. Series 1, ECMWF, Shinfield Park, Reading, UK, 63 pp., 2000.

Solomon, S., Qin, D., Manning, M., Alley, R. B., Berntsen, T., Bindoff, N. L., Chen, Z., Chidthaisong, A., Gregory, J. M., Hegerl, G. C., Heimann, M., Hewitson, B., Hoskins, B. J., Joos, F., Jouzel, J., Kattsov, V., Lohmann, U., Matsuno, T., Molina, M., Nicholls, N., Overpeck, J., Raga, G., Ramaswamy, V., Ren, J., Rusticucci, M., Somerville, R., Stocker, T. F., Whetton, P., Wood, R. A., and Wratt, D.: Technical Summary, in: Climate Change 2007: The Physical Science Basis. Contribution of Working Group I to the Fourth Assessment Report of the Intergovernmental Panel on Climate Change edited by: Solomon, S., Qin, D., Manning, M., Chen, Z., Marquis, M., Averyt, K. B., Tignor, M., and Miller, H. L., Cambridge University Press, Cambridge, United Kingdom and New York, NY, USA, 2007.

Somot, S., Sevault, F., Déqué, M., and Crépon, M.: 21st century climate change scenario for the Mediterranean using a coupled atmosphere-ocean regional climate model, Global Planet. Change, 63, 112-126, 2007.

Trigo, R. M., Garca-Herrera, R., Diaz, J., Trigo, I. F., and Valente, M. A.: How exceptional was the early August 
2003 heatwave in France?, Geophys. Res. Lett., 32, L10701, doi:10.1029/2005GL022410, 2005.

Trigo, I. F., Davies, T. D., and Bigg, G. R.: Objective climatology of cyclones in the Mediterranean region, J. Climate, 12, 16851696, 1999.

Ulbrich, U., May, W., Lionello, P., Pinto, J. G., and Somot, S.: The Mediterranean climate change under global warming, in: Mediterranean Climate Variability, edited by: Lionello, P., Malanotte, P., and Boscolo, R., Elsevier, 399-415, 2006.

Vidal, J. P., Martin, E., Franchistéguy, L., Baillon, M., and Soubeyroux, J. M.: A 50-year high-resolution atmospheric reanalysis over France with the Safran system, Int. J. Climatol., 30, $1627-$ 1644, 2010.

Vautard, R., Cattiaux, J., Yiou, P., Thépaut, J. N., and Ciais, P.: Northern hemisphere atmospheric stilling partly attributed to an increase in surface roughness, Nature Geosci., 3, 756-761, doi:10.1038/ngeo979, 2010.

Vigaud, N., Vrac, M., and Caballero, Y.: Probabilistic downscaling of GCMs scenarios over southern India, Climatic Change, submitted, 2010.

Vrac, M., Marbaix, P., Paillard, D., and Naveau, P.: Non-linear statistical downscaling of present and LGM precipitation and temperatures over Europe, Clim. Past, 3, 669-682, doi:10.5194/cp3-669-2007, 2007a.

Vrac, M., Stein, M., and Hayhoe, K.: Statistical downscaling of precipitation through nonhomogeneous stochastic weather typing, Clim. Res., 34, 169-184, 2007b.
Vrac, M. and Naveau, P.: Stochastic downscaling of precipitation: From dry events to heavy rainfalls, Water Resour. Res., 43, doi:10.1029/2006WR005308 2007.

Wilby, R. L. and Wigley, T. M. L.: Downscaling general circulation model output: a review of methods and limitations, Prog. Phys. Geog., 21, 530-548, 1997.

Wilby, R. L., Dawson, C. W., and Barrow, E. M.: SDSM - a decision support tool for the assessment of regional climate change impacts, Environ. Modell. Softw., 17, 145-157, 2002.

Wilks, D. S.: Multisite downscaling of daily precipitation with a stochastic weather generator, Clim. Res., 11, 125-136, 1999.

Wilks, D. S. and Wilby, R. L.: The weather generation game: a review of stochastic weather models, Progr. Phys. Geogr., 23, 329-357, 1999.

Xoplaki, E., Gonzales-Rouco, F. J., Luterbacher, J., and Wanner, H.: Wet season Mediterranean precipitation variability: influence of large scale dynamics, Clim. Dynam., 23, 63-78, 2004.

Xoplaki, E., Gonzales-Rouco, F. J., Luterbacher, J., and Wanner, H.: Mediterranean summer air temperature variability and its connection to the large-scale atmospheric circulation and SSTs, Clim. Dynam., 20, 723-739, 2003.

Yang, C., Chandler, R. E., and Isham, V. S.: Spatial-temporal rainfall simulation using generalized linear models, Water Resourc. Res., 41, doi:10.1029/2004WR003739, 2005.

Zorita, E. and von Storch, H.: The analog method as a simple downscaling technique: comparison with more complicated methods, J. Climate, 12, 2474-2489, 1999. 